\title{
Monitoring Progress in Child Poverty Reduction: Methodological Insights and Illustration to the Case Study of Bangladesh
}

\author{
José Manuel Roche*
}

January 2013

\begin{abstract}
Important steps have been taken at international summits to set up goals and targets to improve the wellbeing of children worldwide. Now the world also has more and better data to monitor progress. This paper presents a new approach to monitoring progress in child poverty reduction based on the Alkire and Foster adjusted headcount ratio and an array of complementary techniques. A theoretical discussion is accompanied by an assessment of child poverty reduction in Bangladesh based on four rounds of the Demographic Household Survey (1997-2007). Emphasis is given to dimensional monotonicity and decomposability as desirable properties of multidimensional poverty measures. Complementary techniques for analysing changes over time are also illustrated, including the Shapley decomposition of changes in overall poverty, as well as a range of robustness tests and statistical significance tests. The results from Bangladesh illustrate the value added of these new tools and the information they provide for policy. The analysis reveals two paths to multidimensional poverty reduction - either decreasing the incidence of poverty or its intensity - and exposes an uneven distribution of national gains across geographical divisions. The methodology allows an integrated analysis of overall changes yet simultaneously examines progress in each region and in each dimension, retaining the positive features of dashboard approaches. The empirical evidence highlights the need to move beyond the headcount ratio towards new measures of child poverty that reflect the intensity of poverty and multiple deprivations that affect poor children at the same time.
\end{abstract}

Keywords: child poverty, multidimensional poverty, poverty measurement, FGT measures, capability approach, Bangladesh

JEL classification: I32, J13, O1

* Oxford Poverty and Human Development Initiative, Oxford Department of International Development, University of Oxford. Contact details: jose.roche@,qeh.ox.acuk Tel +44 1865271915 Fax +44 (0)1865 281801

This study has been prepared within the OPHI theme on multidimensional poverty.

OPHI gratefully acknowledges support from the UK Economic and Social Research Council (ESRC)/(DFID) Joint Scheme, Robertson Foundation, UNICEF N’Djamena Chad Country Office, Praus, Georg-August-Universität Göttingen, International Food Policy Research Institute (IFPRI), John Fell Oxford University Press (OUP) Research Fund, German Federal Ministry for Economic Cooperation and Development, United Nations Development Programme (UNDP) Human Development Report Office, national UNDP and UNICEF offices, and private benefactors. International Development Research Council (IDRC) of Canada, Canadian International Development Agency (CIDA), UK Department of International Development (DFID), and AusAID are also recognised for their past support. 


\section{Acknowledgements}

The author is grateful without implication for comments on an earlier version of this paper to: Sabina Alkire, Laura Camfield, Jingqing Chai, Enrique Delamonica, Stephan Dercon, Paul Dorman, Dave Gordon, Stephan Klasen, Luzma Montano, Alberto Minujin, Shailen Nandy, Keetie Roelen, Maria Emma Santos, Gaston Yalonetzky, Zaki Wahhaj, and Wei Ha. I am also grateful for helpful discussion on decomposition techniques to Abdelkrim Araar, Suman Seth and Gaston Yalonetzky, and for research assistance with literature review to Christian Oldiges and Ana Mujica. This paper uses data from the Demographic and Health Survey from Bangladesh.

The Oxford Poverty and Human Development Initiative (OPHI) is a research centre within the Oxford Department of International Development, Queen Elizabeth House, at the University of Oxford. Led by Sabina Alkire, OPHI aspires to build and advance a more systematic methodological and economicframework. for reducing multidimensional poverty, grounded in people's experiences and values.

This publication is copyright, however it may be reproduced without fee for teaching or non-profit purposes, but not for resale. Formal permission is required for all such uses, and will normally be granted immediately. For copying in any other circumstances, or for re-use in other publications, or for translation or adaptation, prior written permission must be obtained from OPHI and may be subject to a fee.

Oxford Poverty \& Human Development Initiative (OPHI)

Oxford Department of International Development

Queen Elizabeth House (QEH), University of Oxford

3 Mansfield Road, Oxford OX1 3TB, UK

Tel. +44(0)1865271915 Fax +44(0)1865 281801

ophi@qeh.ox.ac.uk http://ophi.qeh.ox.ac.uk/

The views expressed in this publication are those of the author(s). Publication does not imply endorsement by OPHI or the University of Oxford, nor by the sponsors, of any of the views expressed. 


\section{Introduction}

Important steps have been taken at international summits and conventions to reach consensus and set goals and targets to improve the wellbeing of children worldwide, including the 1989 Convention on the Rights of the Child (CRC), the 1990 World Summit for Children (WSC), the 2002 declaration 'A World Fit for Children' (WFFC), and the Millennium Declaration that led to the Millennium Development Goals (MDGs). Naturally, continuous high-level political commitment is also needed to ensure firm action and adequate resource allocation for substantial progress to be truly achieved. What has been achieved so far? Has progress been evenly attained within each country? Are we reaching or forgetting the poorest of the poor? These are only some of the questions addressed by systems for monitoring progress. These systems allow us to assess whether countries are on the right track and to steer policies in the right direction. Indeed, the growing interest in setting goals and targets has in parallel stimulated data collection and increased the availability of internationally comparable indicators. This has been particularly boosted by major international survey projects such as the Multiple Indicator Cluster Surveys (MICS) and the Demographic Household Survey (DHS). We now have more and better data than we did before. Data are frequently organized in large dashboards of indicators such as the prominent list of over 60 indicators to monitor progress on the MDGs. In addition, the microdata from various survey programs are open access and can be used for more in-depth analysis.

Dashboards provide the opportunity to share comprehensive or holistic analyses, but in practice a large array of indicators may overwhelm or confuse the reader and be difficult to communicate. A large set of indicators also does not provide an overview of progress or capture the multiple deprivations that affect the poor at the same time. The search for synthetic measures, as well as the understanding that a single indicator such as income poverty is not sufficient to fully capture the multiple dimensions of poverty, has boosted the interest in developing techniques for multidimensional poverty (MP) measurement (for an overview on recent developments see: Addison et al. 2009; Asselin et al. 2009; Chiappero-Martinetti and Roche 2009; Duclos and Araar 2006; Kakwani and Silber 2008; Kuklys 2005; Lemmi and Betti 2006). The range of approaches deals in different ways with the methodological challenges of MP measurement. This paper examines a particular approach proposed by Alkire and Foster (2007, 2011a) and looks at how it can be adjusted to child poverty measurement. We shall argue that the clear specification of this approach makes it easy to communicate, which is a useful feature for monitoring purposes. Similarly, this approach satisfies two useful properties which have important policy implications for child poverty measurement: dimensional monotonicity and subgroup decomposability. As will be seen, by satisfying dimensional monotonicity the method moves beyond the headcount ratio, thus overcoming common problems of many child poverty measures (for example: Gordon et al. 2003). The problem is that the headcount ratio remains invariant if a child who is already poor becomes deprived in any another dimension and so the measure does not provide policy incentive to focus on the poorest of the poor. This problem has already been the subject of previous remarks by Delamonica and Minujin (2007). In addition, by satisfying the property of subgroup decomposability one can inform group prioritization or break down the effect of changes over time by subgroup of population, generating an analysis that is useful for policy.

This paper presents this new approach to child poverty measurement. A theoretical discussion is accompanied by an assessment of child poverty reduction in the case study of Bangladesh, based on four rounds of the Demographic Household Survey (1997, 2000, 2004 and 2007). Bangladesh is a particularly interesting case due to its significant gains in human development over the last decade (Lewis 2011; Ranis and Stewart 2010). The paper is structured as follows. The next section discusses the importance of assessing the joint distribution and intensity of poverty. Then, we discuss how to fine-tune a measure for child poverty monitoring and explain the parameters used for the empirical application in this paper. We next assess overall progress in child poverty reduction in Bangladesh and then analyse changes by 
dimensions and present a new integrated analysis using the Shapley decomposition of changes over time. The final section concludes.

\section{The AF method: scrutinizing the joint distribution and intensity of poverty}

The Alkire-Foster (AF) method (2007, 2011a) combines the intuitive 'counting' approach that has a long history of empirical implementation in multidimensional poverty (Atkinson 2003; Erikson 1993; Feres and Mancero 2001; Gordon et al. 2003; Mack 1985) with the literature on axiomatic approaches to multidimensional poverty in welfare economics (Bourguignon and Chakravarty 2003; Chakravarty et al. 1998; Tsui 2002). As a method of multidimensional poverty measurement, the AF method has attracted important interest and a wealth of academic debate in recent years (see in particular the academic forum published in The Journal of Economic Inequality, volume 9, numbers 2 and 3). The most widely known application of the AF method is perhaps the Multidimensional Poverty Index (MPI) of acute global poverty published in The Human Development Report since 2010 (Alkire and Santos 2010; Alkire et al. 2011b; UNDP 2010b). Naturally, the method can also be adapted to other contexts and purposes, such as child poverty measurement, by adopting different specifications, including unit of analysis, choice of dimensions, choice of indicators, dimensional cutoffs, poverty cutoffs and weights. Interesting policy applications at a national level have been undertaken by the government of México (CONEVAL 2010) and Colombia (Angulo Salazar et al. 2011), as well as a preliminary academic exploration in Venezuela (Gallo and Roche 2012, 2011).

The AF method scrutinizes the information provided by the joint distributions of deprivation. In other words, it constructs a profile of each person and assesses in how many dimensions they are simultaneously deprived. While the full technical explanation is given in Appendix 1, we shall briefly describe the intuition behind the method (a more detailed intuitive explanation with regards to child poverty can be found in: Alkire and Roche 2012). Following Sen (1976), the AF method consists of two steps: identification and aggregation. The identification step consists of a dual cutoff approach. First, the deprivation cutoffidentifies if the person is deprived or not in a given dimension. Second, the poverty cutoff $k$ identifies if the person is multidimensionally poor by assessing their vector of weighted deprivations. Anything between a union or intersection approach may be followed. Deprivations in each dimension may be given equal or differential weights depending on various criteria, commonly reflecting the normative importance of each dimension to wellbeing. Finally, the aggregation step results in three interrelated measures. The first is the beadcount ratio $(H)$ which indicates the percentage of people who are multidimensionally poor. The second, named intensity of deprivation among the poor (A), indicates the average percentage of deprivations experienced by the poor (where differential dimensional weights may apply). Finally, the adjusted headcount ratio $\left(M_{0}\right)$, which ranges from 0 to 1 , refers to the ratio of deprivations experienced by the poor over the total potential number of deprivations if the whole population were deprived in all dimensions. Conveniently, the adjusted headcount ratio can also be expressed as the product of the headcount ratio and the intensity of deprivation among the poor $\left(M_{0}=H^{*} A\right)$. $M_{0}$ can be computed for different types of data, including ordinal data (as data on water, sanitation, and housing usually are). When data are cardinal, additional measures can be computed to reflect the depth and severity of multidimensional poverty. As we will see, the adjusted headcount ratio satisfies a series of properties which are relevant for child poverty measurement. However, I will first discuss in more detail the importance of assessing the joint distribution with a practical example.

One might wonder why we need to choose between a dashboard and a MP measure. As Ferreira (2011) has pointed out, "essentially, multidimensional poverty analysis is interesting because the joint distribution of achievements contains more information than the marginal distributions" (2011: 494). While the dashboards offer valuable information for monitoring dimensions separately, they do not capture the multiple deprivations experienced simultaneously by the poor (see also: Alkire et al. 2011a). Table 1 illustrates the argument with an analogous example as in Ferreira and Lugo (2012) which we 
have adapted to the case of under-five child poverty in Bangladesh using the same DHS data and indicators we use later in this paper. Consider Panel A in Table 1 which is equivalent to a dashboard that measures three dimensions separately: health, nutrition and improved sanitation. We see that important gains were achieved in reducing health deprivations in each period with an overall gain that goes from $43.5 \%$ in 1997 to $19.9 \%$ in 2007 . Deprivations in nutrition particularly decreased in the period $1997-$ 2000 from $74.3 \%$ to $62.2 \%$, and then continue decreasing but at a slower pace. Finally, while deprivations in access to improved sanitation decreased over the whole decade, a statistically significant increase was actually observed between 2000 and 2004 from $68.4 \%$ to $79.1 \%$. As MDG indicators, these figures allow us to assess progress in each dimension separately but only provide information about the marginal distribution. We do not know what is happening with children who are deprived in all three dimensions simultaneously.

What does a joint distribution add? Naturally, it is not the same to be deprived in one dimension only as to be deprived in all three at the same time. By looking at the joint distribution (panel B) one can assess what is happening to children who are deprived in multiple dimensions simultaneously. From a rightsbased approach, we might be interested in assessing how many children are completely free of any deprivation (a union approach). Panel B in Table 1 shows an overall increase in the percentage of children free of any deprivation over the whole period, from $6.7 \%$ in 1997 to $17.1 \%$ in 2007, but there was a small deterioration between 2000 and 2004. Alternatively, we might want to prioritize those children deprived in all three dimensions simultaneously as they suffer a higher intensity of poverty (an intersection approach). The story is a rather more positive one with important gains in every period. What these figures show is that conclusions based on the joint distribution are likely to be different. The joint distribution provides an indication of the intensity of poverty and multiple deprivations that affect the poor at the same time. It matters for policy as it allows us to observe those who are multiply deprived and how this is changing over time.

Table 1. Changes over time and comparison between marginal and joint distribution

\begin{tabular}{lcccc}
\hline & $\mathbf{1 9 9 7}$ & $\mathbf{2 0 0 0}$ & $\mathbf{2 0 0 4}$ & $\mathbf{2 0 0 7}$ \\
\hline Panel A. Marginal distribution: \% children under 5 deprived in... & & & \\
Health (1) & 43.5 & 39.8 & 26.7 & 19.9 \\
Nutrition (2) & 74.3 & 62.2 & 61.4 & 58.3 \\
Improved Sanitation (3) & 72.5 & 68.4 & 79.1 & 58.3 \\
Panel B. Joint distribution: \% children under 5... & & & & \\
Non-deprived in any dimension (free of any deprivation) & 6.7 & 11.4 & 9.0 & 17.1 \\
Deprived in all three dimensions simultaneously & 26.6 & 21.1 & 16.3 & 8.6 \\
\hline
\end{tabular}

Source: Author's calculations based on Bangladesh Demographic Health Survey data. The example follows a similar illustration from Atkinson and Lugo (2010) reproduced in Ferreira and Lugo (2012)

Note: (1) Not immunized or did not receive medical treatment when sick; (2) Either underweight, stunted, or wasted; (3) Lack adequate sanitation by the MDG indicator standards.

Incidentally, multidimensional child poverty measures so far focus mainly on the headcount ratio, overlooking some of the policy-relevant information that contains the joint distribution (see discussion in: Alkire and Roche 2012). One example of this is the multidimensional poverty study undertaken by Gordon et al. (2003) published later by UNICEF (2004). This was the first time that a global study of child poverty was undertaken (Alkire and Roche 2012; Delamonica and Minujin 2007). The study contributes by proposing a way to align child poverty measurement with the child rights approach and to implement, insofar as data permitted, indicators and cutoffs for child poverty that reflected the 
definition agreed upon in the World Social Summit in Copenhagen (United Nations 1995). A similar methodological approach was later implemented by the Global Study on Child Poverty and Disparities to produce a range of very valuable country studies (Fajth et al. 2012; UNICEF 2007).

Despite the important contributions of these child poverty studies, by mainly focusing on the headcount ratio, they overlooked the average number of dimensions in which the poor were deprived. Thus, Delamonica and Minujin (2007) proposed a range of measures that also account for the average intensity of deprivation experienced by poor children. They proposed to measure the depth of child poverty, or the average number of deprivations suffered by children, and the severity of child poverty which takes into account the distribution of deprivations (see a technical explanation in Appendix 2). An empirical implementation of these measures on child poverty in Vietnam was undertaken by Roelen et al. (2010) (see the adjustment proposed by the authors in Appendix 2). Similar to Alkire and Foster (2007, 2011a), Delamonica and Minujin (2007) and Roelen et al. (2010) were seeking an analogous solution to FosterGreer-Thorbecke (FGT) income poverty measures (Foster et al. 1984). The advantage of the proposed AF measure - the adjusted headcount ratio - is that it reflects simultaneously the incidence of poverty and the intensity of deprivation among the poor (satisfying the poverty axiom). It provides the basis for a final ranking as well as allowing decomposition by subgroup or breakdown by dimension, yet it is still possible to analyse the incidence and intensity separately. In section 4.3 we shall come back and compare these metrics with empirical results, but let us first explain the theoretical relevance of moving beyond the headcount ratio.

Figure 1. Illustration of the relevance of intensity for policy

Country A: Headcount-only

policy aimed to reduce the headcount ratio
Country B: Equity-focused approach policy oriented to the poorest of the poor
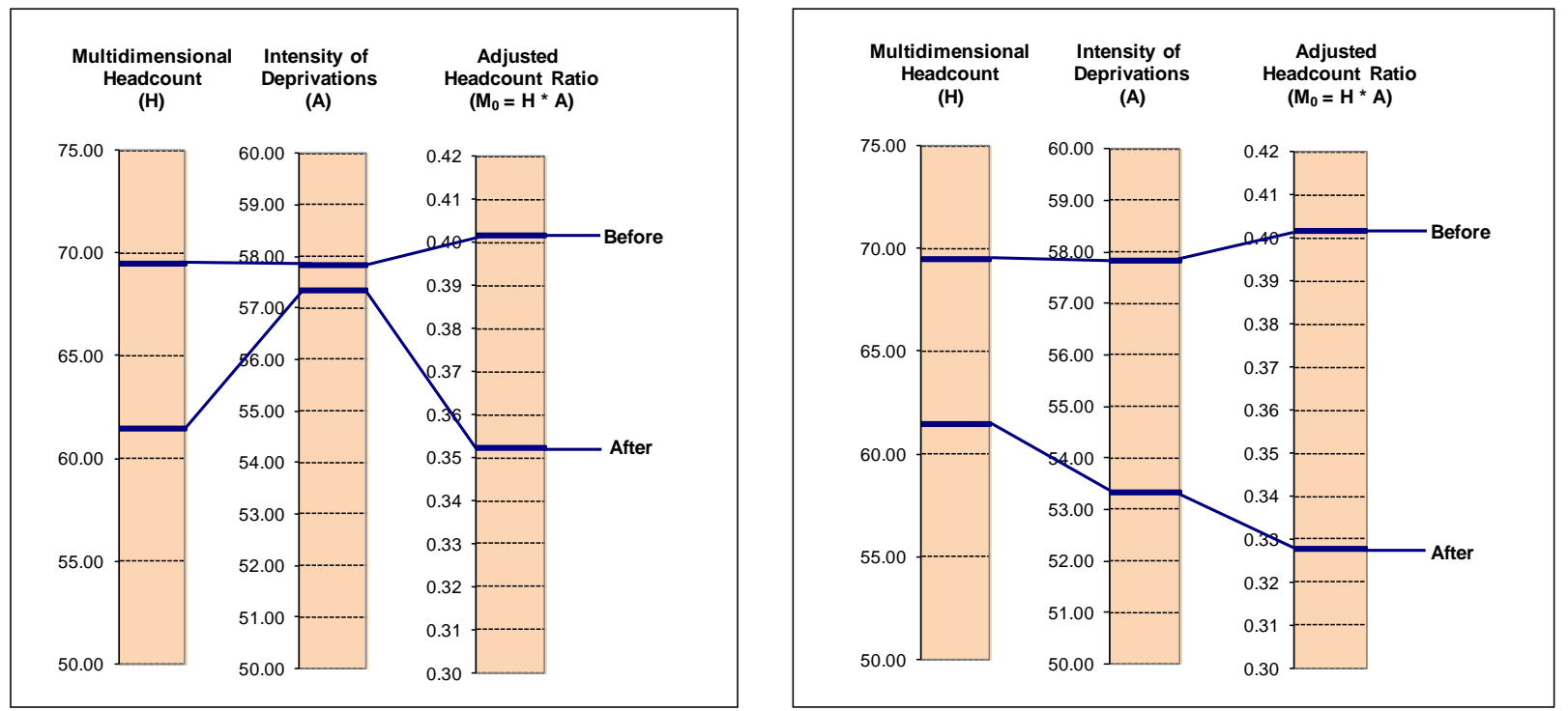
Why is the incidence of deprivations relevant for policy? As in the unidimensional case, the problem with the headcount ratio is that it implicitly creates policy incentives to focus on those that are simply below the poverty line and to ignore the extra burden of poverty experienced by the poorest of the poor (Sen 1976). This is because it does not change if a child who is multidimensionally poor across a period of time becomes deprived in more or fewer dimensions.

Consider two countries with the same initial poverty level but where two very different poverty reduction policies are put into place (Figure 1). In country A, the poverty reduction policy focuses on reducing the headcount ratio, but in country $\mathrm{B}$ the programs are oriented to the poorest of the poor (those experiencing the highest number of deprivations simultaneously). It might well be that after the application of these policies both countries reduce the headcount ratio at the same rate. However, we would expect that in country B where policy prioritizes the poorest of the poor - what UNICEF calls an 'equity-focused' approach and which is central to its purpose (UNICEF 2010) - there would be a more substantial reduction of the intensity of deprivations among the poor, while the intensity of deprivation may not necessarily decrease in country A. If we only look at the headcount ratio, we will conclude that country A performed equally well in comparison to country B. But if we look at the adjusted headcount ratio $\left(\mathrm{M}_{0}\right)$ we may see that country $\mathrm{B}$ has in fact performed better overall as it made important gains in reducing both the incidence of poverty and intensity of deprivations among the poor. This was precisely the motivation of Alkire and Foster (2011a) in proposing the adjusted headcount ratio, which also motivated Delamonica and Minujin (2007) to expand the child poverty measurement work of Gordon et al. (2003). So conceptually it is more appropriate to use the adjusted headcount ratio as this creates stronger policy incentives than the headcount ratio alone. In the following analysis we will illustrate how this also matters in practice, based on the real case of assessing reduction in child poverty in Bangladesh over the period 1997-2007. In the process, we will also show how the properties of subgroup decomposability and dimensional breakdown can be used for policy purposes.

\section{Fine-tuning a measure for monitoring child poverty reduction}

We will now discuss general principles for fine-tuning a measure for monitoring child poverty reduction and explain in the process the specifications that we follow in this paper. We shall start by explaining the rationale for choosing Bangladesh as a case study.

Why Bangladesh? Despite negative views about its development potential in the 1970s and 1980s, Bangladesh has come to be seen as an exceptionally successful story in development and poverty reduction (Lewis 2011). A global comparative analysis of human development progress between 1970 and 2007 by Ranis and Stewart (2010) identified Bangladesh as one of the top five success stories among those countries that started with low levels of human development in the 1970s. The country has made important gains in reducing monetary poverty (World Bank 2008) as well as being among the top 20 countries with regard to progress on the MDGs (ODI 2010). According to Ranis and Stewart (2010), Bangladesh is an example of how countries can overcome their adverse initial conditions via improvements in social expenditure, even with the moderate economic growth that Bangladesh had as compared with other South and Southeast Asian countries. Under-5 mortality fell from 240 per 1,000 live births in 1970 to around 68 per 1,000 in 2005, and life expectancy rose from 44 in 1975 to 65 years by 2005 (Ranis and Stewart 2010). Though extensive malnutrition still exists, Bangladesh is among the countries with the highest rates of absolute progress in reducing the proportion of children under the age of five who are underweight - from 67\% in 1992 to 46\% in 2007 (ODI 2010). Important gains have also been achieved by large-scale immunization programs and by expanding access to improved sanitation facilities (Lewis 2011). There is consensus in attributing significant credit for this success to initiatives undertaken by a strong NGO sector that was initiated by local and international relief efforts during post-conflict reconstruction in 1971 (Lewis 2011; Ranis and Stewart 2010). This all makes Bangladesh an interesting case of study. What new information does a multidimensional poverty 
measure showing the joint distribution of deprivations provide? To what extent is overall progress driven by improvements among the poorest of the poor such as those suffering more simultaneous deprivations? Has progress been evenly achieved across regions? These are only some of the questions that we aim to answer.

Purpose of the measure - Clearly, its purpose determines to a great extent how we ought to fine-tune the measure (Alkire and Foster 2011b). In our case, the academic research question shapes the analysis in a very particular way. If we were designing an official national measure, we might want to prioritize transparency to facilitate accountability and public debate (see for example: Angulo Salazar et al. 2011; Gallo and Roche 2011). Alternatively, if the measure was going to be used by an NGO to monitor changes in the local development context where they work, one may be particularly interested in incorporating a wide range of stakeholders in the design process with particular attention paid to the poor themselves.

Data source - Naturally, the choice of data is not independent to the purpose of the measure either. Available data might be sufficient to answer the research question or one might need further data collection. Incidentally, poverty measures can be useful in stimulating the production of more and better data as was the case of the MDGs and multidimensional poverty measurement in Mexico (CONEVAL 2010). In this paper the analysis is based on four rounds of the Bangladesh Demographic Health Survey (BDHS) covering four points in time: 1997, 2000, 2004 and 2007. The international standards and purposes of the surveys make them especially well-suited for our purposes as they have good quality child-specific indicators to measure health dimensions that are not normally included in living standards household surveys. The BDHS follows a multistage cluster sampling which is designed to provide separate estimates at the national level for urban and rural areas, and for all six regional divisions in Bangladesh: Barisal, Chittagong, Dhaka, Khulna, Rajshahi and Sylhet. ${ }^{1}$

Unit of analysis - It seems obvious that a child poverty measure should have the child as a unit of analysis but one should be aware of the additional challenges this entails. Naturally, the relevant dimensions or what constitutes deprivations depends on the age of the child - for example, school attendance matters for children of school age while in early childhood special attention is given to immunization. What should we do if an indicator does not apply to all age groups? Depending on certain circumstances (for example the purpose of the measure, data availability) one might choose to design a measure that takes into account the life-cycle of the child (see: Roelen et al. 2010) ${ }^{2}$. How can we obtain a final overall measure that is still decomposable by age group and can be broken down by dimensions? One possible alternative is to design age group-specific indices. However, there are always tradeoffs; while age-specific measures may orient specific policy interventions, they would make overall assessment more difficult. In this paper we choose to focus exclusively on under-five children, which allows us to have high-quality indicators of deprivations for every child. The same procedure could be followed for different age groups. If required, we could then later seek an appropriate way to combine these into an overall measure.

Dimensions and subdimensions: moving from a concept to its components - A well-established methodological strategy in social research since the early work by Paul F. Lazarsfeld (1958), consists of dividing complex conceptual constructs into their components or dimensions before one moves to identifying the best

1 The fieldwork activities were conducted during March-August 2007, January-May 2004, November 1999-March 2000, and November 1996-March 1997, respectively. The final sample corresponds to 10,268 households in 2007; 10,053 households in 2004; 10,919 households in 2000; and 9,099 households in 1997. The households and women response rate are, respectively, $99.4 \%$ and $98.4 \%$ in 2007; 99.8 and $98.6 \%$ in 2004; $99.3 \%$ and $96.9 \%$ in 2000; and $99.1 \%$ and $97.8 \%$ in 1997 .

2 By the time of this paper's publishing, the on-going research project from UNICEF, Multiple Overlapping Deprivation Analysis (MODA), was also following a life-cyde approach. 
indicators to measure each dimension. Any effort starts from a conceptual framework that frames our understanding of what we mean by, in our case, child poverty and its dimensions. From a human development or capability perspective, poverty is understood as a lack of fundamental capabilities and the choice of dimensions is seen as a valuation of what constitutes 'the good life' (Sen 1980, 1992). Defining the list of fundamental capabilities is nonetheless a matter of some debate. Nussbaum (2003) proposes a list from a social contract tradition and some account of human rights (this was used for child poverty measurement by: Di Tommaso 2007). However, Sen (2004) prefers an unspecified approach, leaving the definition of capabilities in different contexts and for different purposes to public reasoning and debate. How should we proceed in a measurement exercise? Again, it would depend on the purpose of the measure as "what we focus on cannot be independent of what we are doing and why" (Sen 2004: 79). Useful procedural criteria are suggested by Robeyns (2003) and Alkire (2008). If the aim is an official national measure, one might find appropriate a mixed process that allows some level of consultation and debate yet pays attention to social and economic rights subscribed to by the country (see Burchardt and Vizard 2011). In other cases, further participatory methods could be particularly attractive for a child poverty measure (see: Biggeri et al. 2006; Roelen and Camfield 2012). In this paper we shall follow the conceptualization by Gordon et al. (2003) which was also used in the Global Study on Child Poverty and Disparities (Fajth et al. 2012; UNICEF 2007). This definition follows the international agreement at the World Social Summit in Copenhagen in 1995 (see Table 2) and will allow us to assess the strict value-added of the AF methodology. ${ }^{3}$ Naturally, alternative definitions and choices of dimensions are possible for other purposes - especially if one takes into account the current consultation and debate about post-2015 MDGs.

Indicators - The selection of valid and reliable indicators becomes to a greater extent a matter of technical debate as one moves from theoretical variables (dimensions/subdimensions) to operational variables (indicators). Obviously, a clear conceptualization is required first (i.e. it is not enough to say that 'health' is a component of child poverty; we need to clarify what subdimensions health entails). Once the conceptualization is clear, say for instance by following the Convention on the Rights of the Child, the search for valid and reliable indicators becomes a rather more technical problem, such as defining the best way to measure nutrition (WHO 2006) or improved drinking water or sanitation (WHO/UNICEF 2006). Frequently, there are tradeoffs between the best indicator and those that are possible to measure with the data at hand - but the indicators should not be fully determined by data availability (Dercon 2012; Robeyns 2003). Incidentally, four of the indicators used in the analysis in this paper are also used to measure progress towards specific MDG targets (nutrition, access to improved drinking water, access to improved sanitation), while the indicator for health measures other global goals (see Table 2). From the list, the dimension and indicator for 'information' is the weakest, but we will follow Gordon et al. (2003) to allow comparability.

Weights and robustness checks - The selection of weights is closely linked with the selection of dimensions, as excluding a dimension in practice implies assuming a zero weight. Weights "indicate the relative importance of the different deprivations" (Alkire and Foster 2011b: 295), yet in an index they also affect the marginal rate of substitution between dimensions (Ravallion 2011). There is a wide range of procedures to set up weights, from more participatory methods that allow for deliberation and build consensus, to more statistical ones, which are frequently interlocked with issues of validity and reliability of the selected indicators (see: Roche 2008). If the chosen indicators are valid and reliable measures of the given dimension, then the question of weights turns into strictly a matter of value judgment (see discussion in: Alkire and Foster 2011b). Inevitably, complete consensus cannot be reached so the recommendation is to undertake robustness checks for a range of plausible weights. This paper strictly

3 The 1995 Copenhagen Dedaration and Programme of Action defined poverty as "a condition characterised by severe deprivation of basic human needs, including food, safe drinking water, sanitation facilities, health, shelter, education and information. It depends not only on income but also on access to social services" (United Nations 1995). 
follows the weight structure from Gordon et al. (2003), which attributes equal weight to each dimension. Naturally, this is questionable as we might have reasons to value nutrition or health more than information. The clear specification of the AF method allows for robustness checks of the choice of weights, some of which were undertaken in this paper. The debate on seeking best methodologies to set up weights is certainly ongoing (Alkire and Foster 2011b; Alkire et al. 2011a; Ferreira and Lugo 2012; Koen and Lugo 2010; Ravallion 2011; Roche 2008).

Table 2. Selected indicators and deprivation thresholds

\begin{tabular}{|c|l|}
\hline Dimension & \multicolumn{1}{c|}{ Indicator / Deprivation Thresholds } \\
\hline Nutrition & $\begin{array}{l}\text { Children who are more than two standard deviations below the international reference } \\
\text { population for stunting (height for age), wasting (weight for height) or underweight } \\
\text { (weight for age). The standardization follows the algorithms provided by the WHO Child } \\
\text { Growth Reference Study (WHO 2006). }\end{array}$ \\
\hline Water & $\begin{array}{l}\text { Children using water from an unimproved source such as open wells, open springs or } \\
\text { surface water (distance to water is not included because this information is not available } \\
\text { for BHDS 1997). }\end{array}$ \\
\hline Sanitation & $\begin{array}{l}\text { Children using unimproved sanitation facilities such as a pit latrine without slab, open pit } \\
\text { latrine, bucket toilet and hanging toilet. Surveys were standardized for comparability } \\
\text { following MDG definitions. }\end{array}$ \\
\hline Health & $\begin{array}{l}\text { Children who have not been immunized or received medical treatment when sick. A } \\
\text { child is deprived if the child has not received eight of the following vaccinations (for } \\
\text { under 12 months old at least one vaccination): bcg, dpt1, dpt2, dpt3, polio0, polio1, } \\
\text { polio2, polio3, measles or did not receive treatment for a recent illness involving } \\
\text { diarrhoea. }\end{array}$ \\
\hline Shelter & $\begin{array}{l}\text { Children living in a house with no flooring (i.e. a mud or dung floor) or inadequate } \\
\text { roofing (i.e. thatch, palm leaf or tin). (Overcrowding was not taken into account because } \\
\text { BHDS 1997 does not register the number of rooms used for sleeping). }\end{array}$ \\
\hline Information & $\begin{array}{l}\text { Children with no access to a radio or television (i.e. broadcast media). This indicator } \\
\text { applies only for children above 3 years of age. }\end{array}$ \\
\hline
\end{tabular}

Note: The choice of dimensions and indicators follows, as dosely as possible, Gordon et al. (2003). Education deprivation was not induded because it is not relevant for under-five children. The indicators from the Bristol study "Severe Deprivation of Access to Basic Services" was not available for all four BDHS rounds.

Deprivation cutoff, poverty cutoff and robustness checks - As with the value judgment implicit in the selection of dimensions and weights, there are various procedures for the selection of cutoffs (Alkire and Foster 2011b). Occasionally, some technical criteria may guide the decision, for example the cutoffs in anthropometric measures are the subject of a technical debate (WHO 2006). However, setting up minimum levels is more commonly a matter of a judgment of what is considered acceptable, which may vary depending on the social setting. In this paper we follow the indicator definitions from Gordon et al. (2003) as specified in Table 2 which mainly follows MDG standards. Note that the lists of indicators or minimum thresholds were frequently adjusted to the particular national context of study in the Global Study (Fajth et al. 2012). We consider poverty cutoffs between $\mathrm{k}=2$ and $\mathrm{k}=4$ and report in the table results for $\mathrm{k}=3$. Robustness tests for different $\mathrm{k}$ values were undertaken where specified (see figures $\mathrm{A} 1$ and $\mathrm{A} 2$ in the Appendices. 


\section{Assessing overall progress in poverty reduction}

Let us now analyse the empirical results from Bangladesh. The analysis is organized as follows. We start with an assessment of overall progress at the national level based on the adjusted headcount ratio and examine whether progress has been evenly achieved across regional divisions. Next we analyse changes in the incidence of poverty and intensity of deprivations among the poor and assess the extent to which regions follow different paths to poverty reduction. Then we compare results using the AF measures of intensity of deprivations with the measures proposed by Delamonica and Minujin (2007) and Roelen et al. (2010). In section 5 we move further by taking maximum advantage of two key properties of the adjusted headcount ratio: subgroup decomposability and dimensional breakdown. As will be seen, throughout the paper we check for statistical significance of differences and undertake various robustness tests to the choice of poverty cutoff and dimensional weights.

\subsection{Overall progress at national and regional levels}

An overall assessment of progress at a national level and for each regional division is synthetically presented in Table 3.

Overall national progress: The tendency is a decrease in the first period (1997-2000), with a significant relative variation of $-11 \%$ in the multidimensional child poverty index. We observe an inertia in the second period (2000-2004) with a non-statistically significant reduction. Finally, a high drop is registered in the third period (2004-2007) with a significant variation of $-18 \%$ in the multidimensional child poverty index. In terms of the incidence of deprivation, there was a reduction in the percentage of poor children from $83 \%$ in 1997 to $76 \%$ in 2000 , which implies an absolute statistically significant variation of $-7 \%$. Between 2000 and 2004 the percentage of poverty remained unchanged, but in the period 2004 to 2007 it fell from $76 \%$ to $66 \%$ which represents a statistically significant variation of $-11 \%$. In terms of the intensity of deprivations the picture is rather different. Although the reduction in the intensity is not very high (from $67 \%$ to $61 \%$ in the whole decade), we register a statistically significant reduction in every period including 2000-2004 and the highest reduction in the third period.

Was progress evenly achieved among regional divisions? During the first period (1997-2000), the highest progress is observed in Chittagong, Dhaka and Khulna with a statistically significant relative variation of at least $-12 \%$. During the same period, variation is barely statistically significant in Rajshahi and is not statistically significant in Barisal and Sylhet. Interestingly, during the second period we observe the same national inertia across most divisions except for Sylhet which shows a relative decrease of $14 \%$ that is significant at a less demanding alpha of $\alpha=0.10$ (note that the sample at a division level is smaller, which is why we relax the alpha). Barisal and Chittagong, both low-lying coastal regions and frequently affected by natural disasters (Azam and Imai 2009), appear to increase multidimensional poverty over the period 2000 and 2004 but differences are not statistically significant. The last period shows a very positive story, with a significant relative reduction of at least $17 \%$ in Chittagong, Dhaka, Khulna and Rajshahi and a more modest reduction of $11 \%$ in Barisal (this last one is statistically significant only at $\alpha=0.10$ ). Incidentally, during this last period Sylhet does not show a statistically significant reduction which erodes some of the gains this division achieved in reducing the gap with other divisions during the period 20002004.

In summary, there has been a clear improvement over the whole decade from 1997 to 2007, with some inertia during the period between 2000 and 2004. However, even during this period the intensity of deprivation among the poor was reduced. The fastest pace of poverty reduction was observed in the last period (2004-2007) which, incidentally, occurred during a period of rapid economic growth in the country (World Bank 2012). However, the analysis exposes an uneven distribution of national gains across geographical divisions. Barisal improved at a much slower pace than any other division, so it moved from being the second region in the ranking of lowest child poverty in 1997 to being in the worst 
position in the ranking by 2007. Sylhet, which started as the region with the highest level of poverty, managed to reduce the gap with other regions particularly during the period 2000-2007 when it was the sole region that improved, but it lagged behind between 2004 and 2007. The best progress was observed in Chittagong, Dhaka and Rajshahi which slowly reduced the gap with Khulna, a division that also improved but not at the same pace. Figures A1 and A2 show that this overall assessment is robust to the choice of poverty cutoff $\mathrm{k}$ (further robust ranking comparison can be undertaken with other techinques: Duclos et al. 2006).

\subsection{Different paths to poverty reduction}

The overview of progress provided by the adjusted headcount ratio can be "coherently and consistently deepened and sharpened by the more specific insights contained in decompositions and partial indices" (Alkire and Foster 2011b: 311). We will now analyse two of these partial indices, the headcount ratio and the intensity of deprivation among the poor, in an attempt to identify the different paths to poverty reduction followed by the regional divisions. It is worth recalling that these partial indices are not independent from the adjusted headcount ratio, but they all interrelate as they rely on their joint distribution through the identification step (Alkire and Foster 2011b).

The analysis shows how regional divisions reduced child poverty through different paths (figures are contained in Table 3). Remarkably, Chittagong mainly reduced poverty by decreasing the incidence of poverty but experienced hardly any improvements in the intensity of poverty among the poor. In this division, the reduction in the percentage of poor was statistically significant with an absolute reduction of over $10 \%$ in the first and second period. However, variation in the intensity of poverty was only slightly significant in the second period $(\alpha=0.10)$. In contrast, Dhaka shows statistically significant improvements in decreasing the proportion of multidimensionally poor children as well as in reducing the intensity of deprivation among the poor (even in the period between 2000 and 2004). Sylhet, the only division that showed progress during 2000-2004, reduced child poverty mainly by decreasing the incidence of poverty (with a $-10 \%$ absolute rate of variation), but changes in the intensity of poverty were not statistically significant. Barisal showed insignificant variation in the incidence of poverty across all the periods, but it showed a significant reduction in the intensity of poverty between 1997-2000 and 2004-2007 (only at $\alpha=0.10$ ). Finally, Khulna is a mixed case as it reduced child poverty during 19972000, mainly by decreasing the proportion of poor children, but in the period 2004-2007 important gains were achieved as well by reducing the intensity of deprivation among the poor. In summary, the analysis reveals that regions within Bangladesh are diverse in the extent to which multidimensional poverty reduction occurred by decreasing the incidence of poverty or its intensity. 
Table 3: Level and variation in the Multidimensional Child Poverty Index, Headcount ratio and Intensity of poverty by division in Bangladesh, 1997, 2000, 2004 and 2007

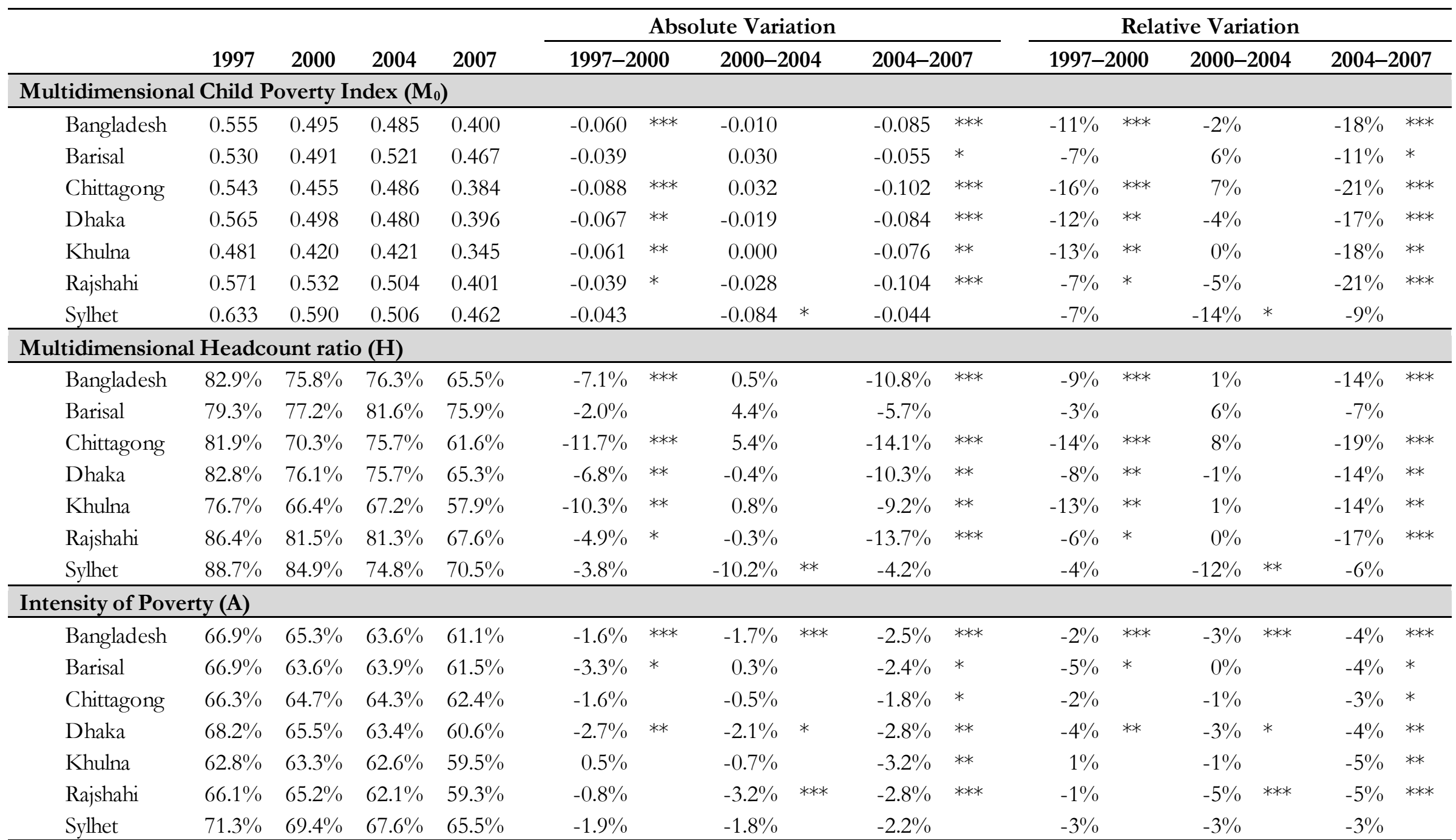

Source: Own calculations based on the Demographic Household Survey.

Note: ${ }^{* * *}$ statistically significant at $\alpha=0.01,{ }^{*}$ statistically significant at $\alpha=0.05, *$ statistically significant at $\alpha=0.10$. It corresponds to a t-test hypothesis test for the difference between both years, taking into account the complex sample design of the surveys. 


\subsection{Comparison with other measures of intensity of child poverty}

We might wonder what conclusions would be obtained if one used instead the measures of intensity of child poverty proposed by Delamonica and Minujin (2007) and Roelen et al. (2010). Table 4 presents a comparison among the different measures at the national level while Table A1 in the Appendix shows the full results at a subnational level. A detailed technical explanation of these different indices is presented in Appendix 2.

Table 4: Comparison among different measures of intensity of child poverty in Bangladesh, 1997, 2000, 2004 and 2007

\begin{tabular}{|c|c|c|c|c|c|c|c|c|c|c|}
\hline & & & & & & Abso & ute Vari & ation & & \\
\hline & 1997 & 2000 & 2004 & 2007 & $1997-2$ & 000 & $2000-2$ & 004 & 2004 & 2007 \\
\hline Bangladesh & & & & & & & & & & \\
\hline 1. Intensity for $\mathrm{k}=1$ (AF) & $61.0 \%$ & $56.9 \%$ & $55.9 \%$ & $50.4 \%$ & $-4.2 \%$ & $* * *$ & $-0.9 \%$ & & $-5.5 \%$ & $* * *$ \\
\hline 2. Intensity for $\mathrm{k}=2(\mathrm{AF})$ & $62.9 \%$ & $60.1 \%$ & $58.5 \%$ & $54.4 \%$ & $-2.7 \%$ & $* * *$ & $-1.6 \%$ & $*$ & $-4.2 \%$ & $* * *$ \\
\hline 3. Intensity for $\mathrm{k}=3$ (AF) & $66.9 \%$ & $65.3 \%$ & $63.6 \%$ & $61.1 \%$ & $-1.6 \%$ & $* * *$ & $-1.7 \%$ & $* * *$ & $-2.5 \%$ & $* * *$ \\
\hline 4. Depth (DM) & 3.6 & 3.3 & 3.3 & 2.9 & -0.3 & $* * *$ & -0.1 & & -0.4 & $* * *$ \\
\hline 5. Depth as $\%$ indicators (RGN) & $59.9 \%$ & $55.6 \%$ & $54.6 \%$ & $48.6 \%$ & $-4.3 \%$ & $* * *$ & $-1.0 \%$ & & $-5.9 \%$ & $* * *$ \\
\hline 6. Weighted Depth (DM) & 14.4 & 12.7 & 12.2 & 10.1 & -1.6 & $* * *$ & -0.6 & & -2.1 & $* * *$ \\
\hline 7. Severity (DM) & 5.0 & 5.0 & 4.7 & 4.5 & -0.1 & $* * *$ & -0.2 & & -0.3 & $* * *$ \\
\hline
\end{tabular}

Source: Own calculations based on Demographic Health Surveys.

Note: $* * *$ statistically significant at $\alpha=0.01,{ }^{* *}$ statistically significant at $\alpha=0.05$, ${ }^{*}$ statistically significant at $\alpha=0.10$.

It corresponds to a t-test hypothesis test for the difference between both years, taking into account the complex sample design of the surveys. AF = Alkire and Foster (2011); DM = Delamonica and Minujin (2007), RGN = Roelen, Gassmann and de Neubourg (2010).

In the first three rows, we present the intensity of deprivation among the poor following Alkire and Foster (2011a) for different poverty cutoff $k$ values: $k=1, k=2$ and $k=3$ (see Appendix 1). As expected from a theoretical point of view, the intensity rises as we increase the poverty cutoff $\mathrm{k}$ value, because we are simply focusing on a set of children who have a higher intensity of deprivation $\left(c_{i}>=k\right)$. However, what is interesting is that changes during the period 2000-2004 are only statistically significant for $\mathrm{k}=2$ and $\mathrm{k}=3$. This suggests that, indeed, there were further improvements among the poorest of the poor which are captured only when we increase $\mathrm{k}$.

The fourth row refers to the depth of child poverty index proposed by Delamonica and Minujin (2007), which aims to measure the intensity of poverty, while the fifth row corresponds to the index used by Roelen et al. (2010), which is equivalent to the former but is expressed as a proportion of the total indicators (in this case over 6). There are two main sources of difference between the intensities as computed in the indices of the fourth and fifth rows and the AF intensity of poverty. First, Delamonica and Minujin (2007) measures the average deprivation experienced by the whole population and not just the poor as in the AF method (see Appendix 1). Second, the AF method allows focusing on the poorest poor by using higher poverty cutoff values $\mathrm{k}$ and thus censoring the deprivations of those who do not meet the required number of simultaneous deprivations. ${ }^{4}$ Theoretically, Delamonica and Minujin (2007) implies that the indices could change by simply increasing the absolute number of non-poor population despite keeping the number of poor population unchanged. So for example, a swap of non-poor population between regions or countries (such as migration) might reduce the indices. This does not

4 An additional difference between poverty intensity in Alkire and Foster (2011a) and in Delamonica and Minujin (2007) is that intensity in Alkire and Foster is expressed as a proportion of the total number of considered dimensions; this is coincident with the Roelen et al. (2010) adjustment. 
happen with the AF intensity index. Interestingly, the empirical example from Bangladesh does not show major differences between both measures when AF intensity follows a union approach. Also, as with $\mathrm{k}=1$, the index from Delamonica and Minujin (2007) does not capture the reduction in the period 20002004.

Finally, indices proposed by Delamonica and Minujin (2007), shown in rows six and seven, expand the index shown in the fourth row, by penalising according to the number of deprivations experienced by the most deprived. This, the authors argue, is equivalent to the squared gap in FGT measures. As Delamonica and Minujin (2007) suggests, the severity index, which is based on the standard deviation, is easier to interpret and shows that roughly one sixth of children suffered from at least five deprivations in 1997, a number that decreased to 4.5 in 2007. It provides useful information despite not satisfying the 'poverty focus' axiom. Delamonica and Minujin's (2007) proposition reminds us that research on further measures of inequality among the poor is needed.

The Appendix A1 shows further comparisons at a subnational level. If we restrict the level of significance to at least $\alpha=0.05$, the conclusions in our analysis seem relatively robust to the choice of measure. Changes only occur when one increases $\mathrm{k}$, which theoretically can be seen as focusing on a set of population with a higher intensity of poverty.

\section{Subgroup decomposition and dimensional breakdown}

In this section we present the results of an integrated analysis of changes over time which takes maximum advantage of two key properties of the adjusted headcount ratio: subgroup decomposability and dimensional breakdown. Until now we have assessed the statistical significance and robustness of changes in the adjusted headcount ratio, as well as in the incidence of poverty and intensity of deprivation among the poor. We performed this analysis separately for Bangladesh and for each regional division within the country. We will next analyse changes in each dimension and its relation to overall poverty reduction. We will then present an integrated analysis based on a Shapley decomposition of changes over time (see Appendix 3).

\subsection{Assessing progress by indicator: from an index to a dashboard}

Let us now analyse changes in the dimensional headcount ratios. In the top panel of Table 5, we present the variations in the raw headcount or in the percentage of people who are deprived in a given dimension. The bottom panel presents the censored headcount or the percentage of people who are poor and deprived in a given dimension according to the identification step. Naturally, in a union approach, the raw and censored headcount will be equal, as it is enough to be deprived in one dimension in order to be identified as multidimensionally poor. So the censored headcount allows us to assess changes among those identified as multidimensionally poor only as opposed to changes among those above the poverty level.

First, overall improvements are observed in all indicators over the decade, with the most remarkable progress occurring in health but with important advances also happening in nutrition and access to improved sanitation. The censored headcount in health reduced from $41 \%$ in 1997 to $18 \%$ in 2007, nutrition from $68 \%$ to $49 \%$ and sanitation from $70 \%$ to $52 \%$. Although Bangladesh started at a lower point, progress in access to drinking water was more modest and not statistically significant, from $5 \%$ to $3 \%$.

Second, during 2000-2004 we observe a mixed story between improvements and deterioration in different indicators, which reminds us that "progress is neither linear or monotonic" (UNDP 2010a: 15). While there was a statistically significant reduction of health deprivation from $37 \%$ to $26 \%$, we observe a 
statistical increase of deprivation in access to improved sanitation from $64 \%$ to $71 \%$. An analysis at the level of regional division (see Tables A2 and A3 in the appendix) shows statistically significant increase in Barisal, Chittagong and Khulna which are the three low-lying coastal regions. Although, to our knowledge, such subnational analyses have not been undertaken before, the results seem coherent with the environmental vulnerability of these regions (Azam and Imai 2009).

Third, by presenting in parallel the raw and censored headcount ratio, we can compare changes across the whole population and changes across those that are identified as multidimensionally poor, according to the poverty cutoff. The most remarkable difference is in the indicator of shelter, where over $90 \%$ of the population experienced deprivation (raw headcount) which is substantially lower when we focus only on deprivations among the poor (censored headcount). Incidentally, in the period 1997-2000 both headcount ratios show statistical significance, but in 2004-2007 only the censored headcount ratio does. This indicates that although deprivations in shelter did not diminish among the whole population, a lesser number of those deprived have an intensity of deprivation that is higher than the poverty line $(k=3)$. There are also some differences in the raw and censored headcount ratios between nutrition and sanitation which indicates that a group of children experiencing these deprivations do not have a joint distribution of deprivation above the poverty line. We might argue that measuring nutrition with stunting puts some focus on past experiences (stock indicator), so those suffering malnutrition in the past might not be multiply deprived later on. Also, we might want to focus on those experiencing deprivation in a given dimension (for example sanitation) who also have other joint deprivations. Alternatively, one might decide to adjust the weights or change the poverty cutoff to modify the implicit assumption (since nutrition is more important than information, we would recommend adjusting the weight in the Global Study: Fajth et al. 2012). At this stage, what matters is that there is a similar trend and statistical significance of the reduction in the raw and censored headcount ratios. The following analysis, which uses a Shapley decomposition, will allow us an even clearer and more integrated analysis. 
Table 5: Level and variation in the raw and censored headcount ratios in Bangladesh, 1997, 2000, 2004 and 2007

\begin{tabular}{|c|c|c|c|c|c|c|c|c|c|c|c|c|c|c|c|c|}
\hline & \multirow[b]{2}{*}{1997} & \multirow[b]{2}{*}{2000} & \multirow[b]{2}{*}{2004} & \multirow[b]{2}{*}{2007} & \multicolumn{6}{|c|}{ Absolute Variation } & \multicolumn{6}{|c|}{ Relative Variation } \\
\hline & & & & & \multicolumn{2}{|c|}{$1997-2000$} & \multicolumn{2}{|c|}{$2000-2004$} & \multicolumn{2}{|c|}{$2004-2007$} & \multicolumn{2}{|c|}{$1997-2000$} & \multicolumn{2}{|c|}{ 2000-2004 } & \multicolumn{2}{|c|}{ 2004-2007 } \\
\hline \multicolumn{17}{|c|}{ Raw Headcount ratio (\% children who are deprived in indicator...) } \\
\hline Health & $43.5 \%$ & $39.8 \%$ & $26.7 \%$ & $19.9 \%$ & $-3.7 \%$ & ** & $-13.2 \%$ & $* * *$ & $-6.7 \%$ & $* * *$ & $-8.4 \%$ & ** & $-33.1 \%$ & $* * *$ & $-25.3 \%$ & $* * *$ \\
\hline Nutrition & $74.3 \%$ & $62.2 \%$ & $61.4 \%$ & $58.3 \%$ & $-12.1 \%$ & $* * *$ & $-0.8 \%$ & & $-3.2 \%$ & $* *$ & $-16.3 \%$ & $* * *$ & $-1.3 \%$ & & $-5.1 \%$ & $* *$ \\
\hline Water & $4.7 \%$ & $3.6 \%$ & $3.4 \%$ & $3.1 \%$ & $-1.1 \%$ & & $-0.2 \%$ & & $-0.3 \%$ & & $-23.0 \%$ & & $-5.8 \%$ & & $-8.1 \%$ & \\
\hline Sanitation & $72.5 \%$ & $68.4 \%$ & $79.1 \%$ & $58.3 \%$ & $-4.1 \%$ & $* *$ & $10.7 \%$ & $* * *$ & $-20.7 \%$ & $* * *$ & $-5.7 \%$ & $* *$ & $15.7 \%$ & $* * *$ & $-26.2 \%$ & $* * *$ \\
\hline Shelter & $95.9 \%$ & $94.1 \%$ & $94.6 \%$ & $93.5 \%$ & $-1.8 \%$ & $* *$ & $0.6 \%$ & & $-1.1 \%$ & & $-1.9 \%$ & $* *$ & $0.6 \%$ & & $-1.2 \%$ & \\
\hline Information & $68.5 \%$ & $65.3 \%$ & $62.2 \%$ & $58.7 \%$ & $-3.2 \%$ & $*$ & $-3.1 \%$ & $*$ & $-3.5 \%$ & $*$ & $-4.7 \%$ & $*$ & $-4.7 \%$ & $*$ & $-5.6 \%$ & $*$ \\
\hline Health & $41.3 \%$ & $37.1 \%$ & $25.5 \%$ & $18.3 \%$ & $-4.1 \%$ & ** & $-11.7 \%$ & $* * *$ & $-7.2 \%$ & *** & $-10.0 \%$ & ** & $-31.4 \%$ & $* * *$ & $-28.2 \%$ & *** \\
\hline Nutrition & $68.4 \%$ & $56.0 \%$ & $55.7 \%$ & $48.5 \%$ & $-12.5 \%$ & $* * *$ & $-0.3 \%$ & & $-7.2 \%$ & $* * *$ & $-18.2 \%$ & $* * *$ & $-0.5 \%$ & & $-12.9 \%$ & $* * *$ \\
\hline Water & $4.6 \%$ & $3.4 \%$ & $3.3 \%$ & $2.9 \%$ & $-1.2 \%$ & & $-0.1 \%$ & & $-0.3 \%$ & & $-27.1 \%$ & & $-3.2 \%$ & & $-10.6 \%$ & \\
\hline Sanitation & $69.8 \%$ & $63.8 \%$ & $70.8 \%$ & $52.0 \%$ & $-6.0 \%$ & $* * *$ & $7.0 \%$ & $* * *$ & $-18.8 \%$ & $* * *$ & $-8.7 \%$ & $* * *$ & $11.0 \%$ & $* * *$ & $-26.5 \%$ & $* * *$ \\
\hline Shelter & $82.6 \%$ & $75.4 \%$ & $76.1 \%$ & $65.3 \%$ & $-7.3 \%$ & $* * *$ & $0.7 \%$ & & $-10.8 \%$ & $* * *$ & $-8.8 \%$ & $* * *$ & $1.0 \%$ & & $-14.2 \%$ & $* * *$ \\
\hline Information & $66.0 \%$ & $61.3 \%$ & $59.5 \%$ & $52.9 \%$ & $-4.7 \%$ & $* * *$ & $-1.8 \%$ & & $-6.6 \%$ & $* * *$ & $-7.1 \%$ & $* * *$ & $-2.9 \%$ & & $-11.2 \%$ & $* * *$ \\
\hline
\end{tabular}

Source: Own calculations based on Demographic Health Surveys.

Note: *** statistically significant at $\alpha=0.01$, ** statistically significant at $\alpha=0.05, *$ statistically significant at $\alpha=0.10$. It corresponds to a t-test hypothesis test for the difference between both years, taking into account the complex sample design of the surveys. 


\subsection{Decomposing variation in poverty reduction by its components}

We now present an integrated analysis based on a Shapley decomposition of changes over time following Shorrocks (1999). This analysis will allow us to systematically assess how much of the overall change is due to poverty reduction in each regional division and how much of the overall change is due to reducing the incidence of multidimensional poverty or decreasing the intensity of poverty among the poor and in which dimension. The technical explanation of the Shapley value decomposition is included in Appendix 2 while the results of the analysis are synthetically presented in Table 6.

Table 6: Shapley decomposition of change in multidimensional child poverty in Bangladesh

\begin{tabular}{|c|c|c|c|c|c|c|c|}
\hline & Barisal & Chittagong & Dhaka & Khulna & Rajshahi & Sylhet & Bangladesh \\
\hline \multicolumn{8}{|c|}{ Overall variation in Multidimensional Child Poverty - 1997/2007 } \\
\hline Multidimensional child poverty $\left(\mathrm{M}_{0}\right)$ in 1997 & 0.530 & 0.543 & 0.565 & 0.481 & 0.571 & 0.633 & 0.555 \\
\hline Multidimensional child poverty $\left(\mathrm{M}_{0}\right)$ in 2007 & 0.467 & 0.384 & 0.396 & 0.345 & 0.401 & 0.462 & 0.400 \\
\hline Absolute variation 1997/2007 & $-6.4 \%$ & $-15.9 \%$ & $-16.9 \%$ & $-13.7 \%$ & $-17.0 \%$ & $-17.1 \%$ & $-15 \%$ \\
\hline Relative variation 1997/2007 & $-12.0 \%$ & $-29.2 \%$ & $-29.9 \%$ & $-28.4 \%$ & $-29.8 \%$ & $-27.0 \%$ & $-28 \%$ \\
\hline \multicolumn{8}{|l|}{ Total Poor Children (in millions) $^{1}$ : } \\
\hline 1997 & 0.8 & 3.0 & 4.0 & 1.2 & 2.8 & 0.9 & 12.9 \\
\hline 2007 & 0.8 & 2.2 & 3.4 & 1.0 & 2.5 & 1.0 & 10.9 \\
\hline \multicolumn{8}{|l|}{$\%$ shared (based on 2007 figures): } \\
\hline Population $^{1}$ & $6.5 \%$ & $21.1 \%$ & $31.4 \%$ & $10.0 \%$ & $22.1 \%$ & $8.9 \%$ & $100 \%$ \\
\hline Multidimensional Headcount ratio $(\mathrm{H})$ & $7.5 \%$ & $19.9 \%$ & $31.3 \%$ & $8.8 \%$ & $22.9 \%$ & $9.6 \%$ & $100 \%$ \\
\hline Multidimensional Child Poverty Index $\left(\mathrm{M}_{0}\right)$ & $7.6 \%$ & $20.3 \%$ & $31.1 \%$ & $8.6 \%$ & $22.2 \%$ & $10.3 \%$ & $100 \%$ \\
\hline \multicolumn{8}{|c|}{ Decomposition variation in Multidimensional Child Poverty (Period 1997/2000) } \\
\hline Total $\%$ contribution $\left(\Delta \mathrm{M}_{0}\right.$ Bangladesh $\left.=100\right)$ & $3.5 \%$ & $31.5 \%$ & $34.1 \%$ & $9.4 \%$ & $21.0 \%$ & $0.4 \%$ & $100 \%$ \\
\hline$\rightarrow$ Demographic effect & $0.8 \%$ & $8.5 \%$ & $-0.1 \%$ & $0.5 \%$ & $-2.8 \%$ & $-8.2 \%$ & $-1.4 \%$ \\
\hline$\rightarrow$ Within-group effect: & $2.7 \%$ & $23.1 \%$ & $34.3 \%$ & $8.9 \%$ & $23.8 \%$ & $8.6 \%$ & $101.4 \%$ \\
\hline$\rightarrow$ Incidence of poverty effect $(\mathrm{H})$ & $0.9 \%$ & $19.0 \%$ & $22.9 \%$ & $7.4 \%$ & $16.5 \%$ & $6.2 \%$ & $73.0 \%$ \\
\hline$\rightarrow$ Intensity of poverty effect $(\mathrm{A})$ : & $1.8 \%$ & $4.0 \%$ & $11.4 \%$ & $1.5 \%$ & $7.3 \%$ & $2.3 \%$ & $28.4 \%$ \\
\hline$\rightarrow$ Health effect (in reducing intensity) & $0.8 \%$ & $3.6 \%$ & $6.1 \%$ & $1.5 \%$ & $4.3 \%$ & $1.1 \%$ & $17.3 \%$ \\
\hline$\rightarrow$ Nutrition (in reducing intensity) & $0.7 \%$ & $1.2 \%$ & $1.9 \%$ & $0.9 \%$ & $1.2 \%$ & $0.8 \%$ & $6.6 \%$ \\
\hline$\rightarrow$ Water (in reducing intensity) & $0.5 \%$ & $-0.7 \%$ & $0.6 \%$ & $-0.5 \%$ & $0.8 \%$ & $0.4 \%$ & $1.1 \%$ \\
\hline$\rightarrow$ Sanitation (in reducing intensity) & $0.1 \%$ & $0.2 \%$ & $2.1 \%$ & $-0.4 \%$ & $1.6 \%$ & $0.4 \%$ & $4.0 \%$ \\
\hline$\rightarrow$ Shelter (in reducing intensity) & $0.0 \%$ & $0.1 \%$ & $0.0 \%$ & $0.0 \%$ & $-0.1 \%$ & $0.0 \%$ & $-0.1 \%$ \\
\hline$\rightarrow$ Information (in reducing intensity) & $-0.3 \%$ & $-0.3 \%$ & $0.8 \%$ & $0.0 \%$ & $-0.4 \%$ & $-0.4 \%$ & $-0.7 \%$ \\
\hline
\end{tabular}

Source: Own calculations based on Demographic Health Surveys.

Note: ${ }^{1}$ Figures are based on percentage distribution of under-5 children using sampling weights and population figures from United Nations, Department of Economic and Social Affairs, Population Division (2011). World Population Prospects: The 2010 Revision, CD-ROM Edition.

Has poverty been reduced in absolute numbers? In the top of the table we report again the overall variation in multidimensional child poverty $\left(\mathrm{M}_{0}\right)$ that was discussed in section 4 and just below that, the total number of poor children in the initial and final period. The figures show that the $28 \%$ relative reduction in the adjusted headcount ratio for Bangladesh was indeed faster than the population growth and so the absolute number of under-5 poor children was reduced from 12.9 million in 1997 to 10.9 million by 2007. The story is not less optimistic across regions. In Chittagong and Dhaka, where we observed some 
of the fastest pace of poverty reduction, there is also a decrease in the absolute number of poor children from $3 \mathrm{M}$ to $2.2 \mathrm{M}$ and from $4 \mathrm{M}$ to $3.4 \mathrm{M}$, respectively. Barisal and Sylhet reduced poverty at a lower rate than population growth and so the absolute number of poor children remained invariant or may have even increased. There was some reduction, if less remarkable, in absolute numbers in Khulna and Rajshahi.

How much has each division contributed to overall reduction in child poverty in Bangladesh? The contribution of each division to overall child poverty is a function of the pace of poverty reduction, the initial poverty level and the size and population growth of each region. The Shapley decomposition results at the bottom of Table 6 show the contribution of each region to the overall reduction of poverty in Bangladesh, which is further decomposed at a first level by demographic effect and within-group effect (see arrows). The demographic effect reflects changes in poverty that arise from shifts in population share that are the result of a faster or slower rate of population growth with respect to other divisions (this may be the consequence of migration dynamics or differences in mortality and/or birth rate). Naturally, from a policy perspective, one is interested in assessing separately the marginal effect that is due to a reduction of poverty levels in each specific subgroup as captured by the within-group effect. The analysis shows some interesting findings. Chittagong and Dhaka have a high contribution to overall poverty reduction in Bangladesh of $23 \%$ and 34\%, respectively. Naturally, we would expect these two populous divisions to contribute significantly, but, in fact, they contributed more than their population shares. Incidentally, Chittagong contributed a further $8 \%$ as a consequence of a share of population switch. Barisal is the opposite case, where it contributed only $2.7 \%$ to poverty reduction in Bangladesh which is much lower than its population share $(7 \%)$. Sylhet, a division that did not reduce the number of absolute poor, in fact contributed $8.6 \%$ to poverty reduction in the country but this was undermined by a faster population growth with respect to other divisions. Rajshahi and Khulna contributed to poverty reduction an equivalent percentage to their population and multidimensional poverty share, with $23.8 \%$ and $8.9 \%$ respectively. The marginal results for Bangladesh show, that if we extract the marginal demographic effect, multidimensional poverty would have been reduced another $1.4 \%$. The bottom line of this analysis is again that Chittagong and Dhaka stand out as successful stories while Barisal has lagged behind.

Figure 2: Shapley decomposition of changes in the variation of the adjusted headcount ratio by variation in incidence and intensity of poverty among the poor, Bangladesh 1997-2007

What about the contribution of incidence and intensity? The Shapley decomposition in Table 6 shows, on a second level, how much of the within-group effect is due to a marginal effect in reducing the incidence of poverty and how much is due to reducing the intensity of poverty among the poor (see equation 14 in Appendix 3). For example, from the $23 \%$ that Chittagong contributed to poverty reduction in Bangladesh, $19 \%$ is due to a reduction in the incidence of poverty effect and only $4 \%$ is due to an intensity effect. In

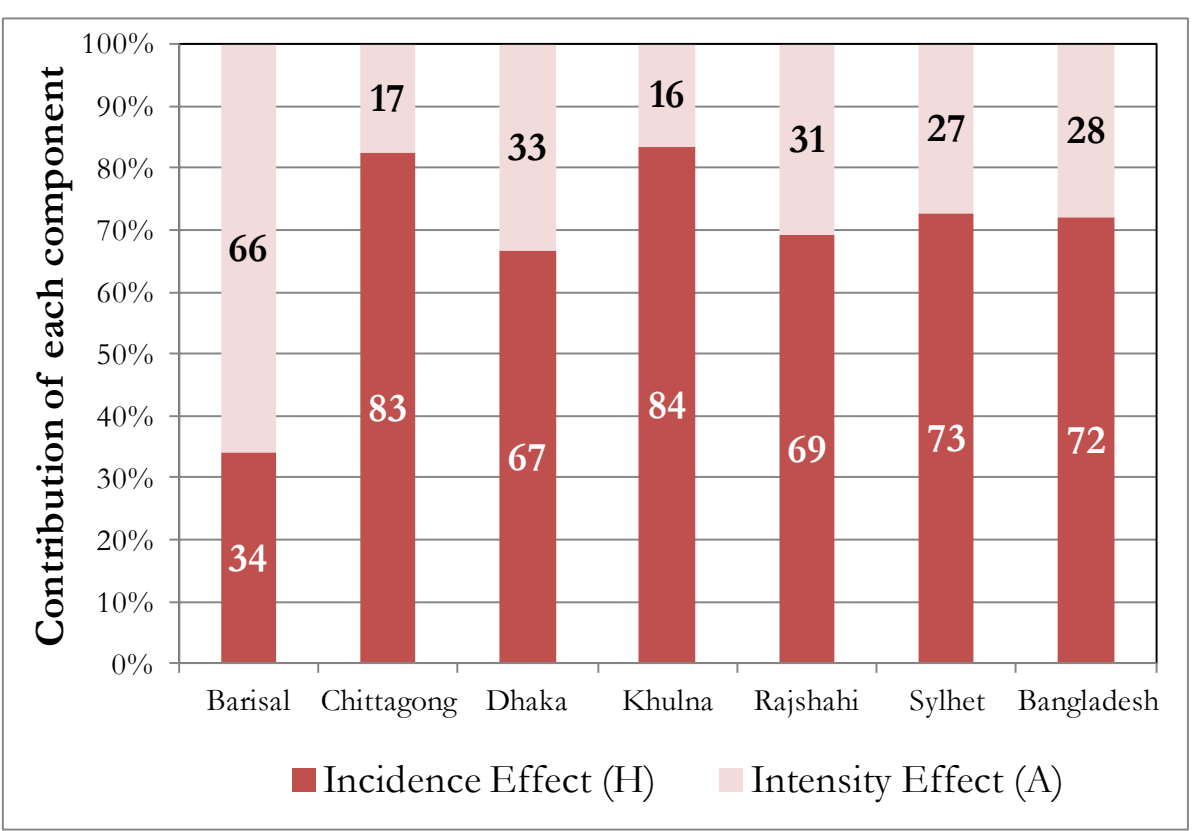


contrast, $11.4 \%$ of poverty reduction in the whole of Bangladesh is exclusively the effect of reducing the intensity of deprivation among the poor in Dhaka while a further $22.9 \%$ is due to reducing the number of multidimensionally poor in this division. Figure 2 presents the same Shapley decomposition but expressed as a percentage of the within-group effect for each division. It stands out how in Barisal, for the small progress achieved, $66 \%$ was the result of a reduction in intensity of poverty among the poor. In Chittagong and Khulna the contribution of a variation in intensity to overall poverty reduction was below average with $17 \%$ or less, while poverty reduction in Dhaka, Khulna and Sylhet show an average contribution of intensity effect. This analysis confirms that the regional divisions followed two different paths to poverty reduction, either by reducing the incidence of poverty or the intensity of deprivations among the poor.

How has the profile of deprivation among the poor changed? One of the desirable properties satisfied by the adjusted headcount ratio is that, after the identification step, it can be broken down by dimension. This property is particularly useful when analysing changes over time as one might be interested in understanding the linkages between dimensional variations and changes in overall poverty. The analysis of changes in the raw and censored headcount ratios in the previous section has already given us some insights on what dimensions were the drivers of the overall change. In the Shapley decomposition in Table 6 we move slightly further by calculating the contribution of each dimension to changes in $\mathrm{M}_{0}$ via reducing the intensity of deprivations among the poor (see equation 16 and 17 in Appendix 3). In the marginal of the table we observe that for the $28.4 \%$ that intensity contributed to poverty reduction in Bangladesh, a total of $17.3 \%$ was due to a health effect, $6.6 \%$ to a nutrition effect, $4 \%$ to a sanitation effect and only $1.1 \%$ to water effect. This decomposition shows us how the profile of deprivations among the poor is changing in Bangladesh. The poor are considerably less deprived in health, nutrition and sanitation by 2007 in comparison to how they were in 1997. Very little happened in terms of shelter or information (if at all, the poor are slightly relatively more deprived in these dimensions as an effect of reductions in the others dimensions).

The analysis by division provides further insights. In Barisal, where modest poverty reduction was mainly driven by decreasing intensity, the poor are less deprived in health, nutrition and water by 2007 . Incidentally, Barisal made some of the highest improvements in reducing deprivation in access to water from $9.9 \%$ in 1997 to 2.5\% in 2007 (see Table A3 in the Appendix), but deprivations in other dimensions still remain relatively high. In Chittagong and Khulna reduction in intensity was mostly driven by health and nutrition, but little was achieved in other dimensions. The remaining divisions follow a pattern similar to the average in the country.

\section{Conclusions}

This paper has presented a new approach to monitoring progress in child poverty reduction, based on the AF adjusted headcount ratio and an array of complementary techniques. This new method combines the intuitive 'counting' approach commonly used in child poverty measurement with the literature on axiomatic approaches to multidimensional poverty in welfare economics. Throughout the paper, particular attention was given to dimensional monotonicity and decomposability as desirable properties of multidimensional child poverty measures. We also presented a range of complementary techniques for analysing changes over time, including a Shapley decomposition, as well as a range of robustness tests and statistical significance tests. The methodology, as illustrated with the results from Bangladesh, allows an integrated analysis of overall changes yet simultaneously examines progress by subgroup of population and in each dimension, retaining the positive features of dashboard approaches. The empirical evidence highlights the need to move beyond the headcount ratio towards new measures of child poverty that reflect the intensity of poverty and multiple deprivations that simultaneously affect poor children. 
The value added of these new tools and the information they provide for policy was illustrated with an analysis of child poverty reduction in Bangladesh. We observed a clear reduction in under-5 child poverty in the country between 1997 and 2007, yet the analysis exposed an uneven distribution of national gains across geographical divisions. Barisal improved at a much slower pace than any other division, while Chittagong, Dhaka and Rajshahi showed important improvements. The results also revealed different paths to multidimensional poverty reduction; this was particularly evident in the integrated analysis undertaken with the Shapley decomposition of changes over time. We observed that Chittagong and Dhaka contributed to overall poverty reduction in the country more than their national population share. In contrast Barisal lagged behind, contributing less than half its national population share. We also confirmed how poverty can be reduced by either decreasing the incidence of poverty or by reducing the intensity of deprivation among the poor. While Chittagong and Khulna mainly reduced the percentage of children in poverty, poverty reduction in Barisal was mainly driven by decreasing the intensity of deprivations among the poor, especially in health, nutrition and water. We saw that $11 \%$ of poverty reduction in the whole of Bangladesh was the exclusive effect of reducing the intensity of deprivations among the poor in Dhaka, while a further $23 \%$ was due to reducing the number of multidimensionally poor in this same division. The analysis also showed that declines in deprivations among the poor in Bangladesh were to a greater extent driven by reducing deprivations in health, nutrition and sanitation. We have particularly explained that the integrated analysis with Shapley decomposition takes full advantage of subgroup decomposability and breakdown by dimensions. While we chose to analyse changes across regional divisions in this paper, it would equally be possible to assess if progress was evenly achieved among other relevant social groups. This would allow us to assess whether the poorest and most-deprived groups are catching up with better-off groups in the country.

Naturally, the approach presented in this paper cannot answer all relevant questions. Other methodologies on multidimensional poverty measurement may complement the analysis by providing further insights such as providing robust multidimensional rankings, by further inspecting distributional issues, by implementing fuzzy cutoffs, or by dealing in different ways with issues of measurement error, just to mention a few research questions. Nonetheless, we have argued that the clear specification of the AF approach makes it easy to communicate, which is a useful feature for monitoring purposes. While challenges remain when defining the parameters to fine-tune the measure, the approach is transparent and open to scrutiny which may stimulate necessary public debate. Naturally, monitoring progress is only part of the research agenda. We also need further multidimensional analyses to understand the mechanisms that facilitate overcoming poverty or are interlocked in reproducing it. We hope that the methodology proposed in this paper contributes by stimulating more holistic approaches to better understand and tackle child poverty. 


\section{References}

Addison, T., D. Hulme and S. M. R. Kanbur (2009) Poverty Dynamics: Interdisciplinary Perspectives. Oxford: Oxford University Press.

Alkire, S. (2008) Choosing Dimensions: The Capability Approach and Multidimensional Poverty. In Kakwani, N. and J. Silber (Eds.) The Many Dimensions of Poverty. New York: Palgrave Macmillan.

Alkire, S. and J. Foster (2007) Counting and Multidimensional Poverty Measurement. OPHI Working Paper No. 7, Oxford: University of Oxford.

Alkire, S. and J. Foster (2011a) Counting and Multidimensional Poverty Measurement. Journal of Public Economics, 95(7-8): 476-487.

Alkire, S. and J. Foster (2011b) Understandings and Misunderstandings of Multidimensional Poverty Measurement. Journal of Economic Inequality, 9(2): 289-314.

Alkire, S., J. Foster and M. Santos (2011a) Where Did Identification Go? Journal of Economic Inequality, 9(3): 501-505.

Alkire, S. and J. M. Roche (2012) Beyond Headcount: Measures That Reflect the Breadth and Components of Child Poverty. In Minujin, A. and S. Nandy (Eds.) Global Child Poverty and Well-Being. Measurement, Concepts, Policy and Action. Bristol: The Policy Press.

Alkire, S., J. M. Roche, M. E. Santos and S. Seth (2011b) Multidimensional Poverty Index 2011: Brief Methodological Note. Oxford Poverty and Human Development Initiative (OPHI). Available at: www.ophi.org.uk/multidimens ional-poverty-index/.

Alkire, S. and M. E. Santos (2010) Acute Multidimensional Poverty: A New Index for Developing Countries. OPHI Working Paper No. 38, Oxford: University of Oxford

Angulo Salazar, R. C., Y. Diaz Cuervo and R. Pardon Pinzon (2011) Índice De Pobreza Multidimensional Para Colombia (Ipm-Colombia) 1997-2010. Archivos de Economia, Documento 382. República de Colombia, Departamento de Planeación Nacional, Dirección de Estudios Económicos.

Apablaza, M. and G. Yalonetzky (2011) Measuring the Dynamics of Multiple Deprivations among Children: The Cases of Andhra Pradesh, Ethiopia, Peru and Vietnam. Young Lives Research in Progress, Oxford: University of Oxford.

Asselin, L.-M., J.-B. Ki and V. T. Anh (2009) Analysis of Multidimensional Poverty: Theory and Case Studies. New York: Springer.

Atkinson, A. B. (2003) Multidimensional Deprivation. Contrasting Social Welfare and Counting Approaches. Journal of Economic Inequality, 1(51-65).

Atkinson, A. B. and M. A. Lugo (2010) Growth, Poverty and Distribution in Tanzania. International Growth Centre, Working Paper 10/0831.

Azam, M. S. and K. Imai (2009) Vulnerability and Poverty in Bangladesh. Working Paper No. 141, Chronic Poverty Research Centre, Manchester: University of Manchester.

Biggeri, M., R. Libanora, S. Mariani and L. Menchini (2006) Children Conceptualizing Their Capabilities: Results of a Survey Conducted During the First Children's World Congress on Child Labour. Journal of Human Development, 7(1): 59 - 83.

Bourguignon, F. and S. R. Chakravarty (2003) The Measurement of Multidimensional Poverty. Journal of Economic Inequality, 1(1): 25-49.

Burchardt, T. and P. Vizard (2011) Operationalizing the Capability Approach as a Basis for Equality and Human Rights Monitoring in Twenty-First-Century Britain. Journal of Human Development and Capabilities, 12(1): 91-119.

Chakravarty, S. R., D. Mukherjee and R. R. Renade (1998) On the Family of Subgroup and Factor Decomposable Measures of Multidimensional Poverty. Research on Economic Inequality, 8(175194).

Chiappero-Martinetti, E. and J. M. Roche (2009) Operationalization of the Capability Approach, from Theory to Practice: A Review of Techniques and Empirical Applications. In Chiappero-Martinetti, E. (Ed.) Debating Global Society: Reach and Limits of the Capability Approach. Milan: Fondazione Feltrinelli.

CONEVAL (2010) Methodology for Multidimensional Poverty Measurement in Mexico. Mexico: Consejo Nacional para la Evaluacion de la Politica Nacional. 
Delamonica, E. E. and A. Minujin (2007) Incidence, Depth and Severity of Children in Poverty. Social Indicators Research, 82(2): 361-374.

Dercon, S. (2012) Understanding Child Poverty in Developing Countries: Measurement and Analysis. In Boyden, J. and M. Bourdillon (Eds.) Childhood Poverty: Multidisciplinary Approaches. Basingtoke, UK: Palgrave Macmillan.

Di Tommaso, M. L. (2007) Children Capabilities: A Structural Equation Model for India. The Journal of Socio-Economics, 36: 436-450.

Duclos, J.-Y. and A. Araar (2006) Poverty and Equity: Measurement, Policy and Estimation with Dad. New York: Springer; Ottawa: International Development Research Centre.

Duclos, J.-Y., D. E. Sahn and S. D. Younger (2006) Robust Multidimensional Poverty Comparisons. Economic Journal, 116(514): 943-968.

Erikson, R. (1993) Descriptions of Inequality. The Swedish Approach to Welfare Research. In Nussbaum, M. and A. Sen (Eds.) The Quality of Life. Oxford: Clarendon Press.

Fajth, G., S. Kurukulasuriya and S. Engilbertsdottir (2012) A Multidimensional Response to Tackling Child Poverty and Disparities: Reflections from the Global Study on Child Poverty and Disparities. In Minujin, A. and S. Nandy (Eds.) Global Child Poverty and Well-Being. Measurement, Concepts, Policy and Action. Bristol: The Policy Press.

Feres, J. C. and X. Mancero (2001) El Método De Las Necesidades Básicas Insatisfechas (Nbi) Y Sus Aplicaciones a América Latina. Series Estudios Estadísticos y Prospectivos, ECLAC-United Nations.

Ferreira, F. (2011) Poverty Is Multidimensional. But What Are We Going to Do About It? Journal of Economic Inequality, 9(3): 493-495.

Ferreira, F. H. G. and M. A. Lugo (2012) Multidimensional Poverty Analysis: Looking for a Middle Ground. World Bank Policy Research Working Paper No. 5964

Foster, J., J. Greer and E. Thorbecke (1984) A Class of Decomposable Poverty Measures. Econometrica, 52(3): 761-766.

Gallo, C. and J. M. Roche (2011) Las Dimensiones De La Pobreza En Venezuela Y Sus Cambios Entre 1997 Y 2010: Propuesta De Una Medida Multidimensional. Serie de Documentos No 126 Caracas: Banco Central de Venezuela. .

Gallo, C. and J. M. Roche (2012) Análisis Multidimensional De La Pobreza En Venezuela Por Entidades Federales Entre 2001 Y 2010. Serie de Documentos No 131: Caracas: Banco Central de Venezuela. .

Gordon, D., S. Nandy, C. Pantazis, S. Pemberto and P. Townsend (2003) Child Poverty in the Developing World. Bristol: The Policy Press.

Kakwani, N. and J. Silber (Eds.) (2008) Quantitative Approaches to Multidimensional Poverty Measurement, Basingstoke: Palgrave Macmillan.

Koen, D. and M. A. Lugo (2010) Weights in Multidimensional Indices of Well-Being: An Overview. Discussion Paper. Katholieke Universiteit Leuven, Centrum voor Economische Studiën.

Kuklys, W. (2005) Amartya Sen's Capability Approach: Theoretical Insights and Empirical Applications. Berlin: Springer.

Lazarsfeld, P. F. (1958) Evidence and Inference in Social Research. Daedalus, 87(4): 99-130.

Lemmi, A. and G. Betti (2006) Fuzzy Set Approach to Multidimensional Poverty Measurement. New York: Springer.

Lewis, D. (2011) Bangladesh: Politics, Economy and Civil Society. Cambridge: Cambridge University Press.

Mack, J., Lansley, S. (1985) Poor Britain. London: George Allen and Unwin Ltd.

Nussbaum, M. (2003) Capabilities as Fundamental Entitlements: Sen and Social Justice. Feminist Economics $9(2 / 3): 33-59$.

ODI (2010) Millenium Development Goals Report Card: Measuring Progress across Countries. London: Overseas Development Institute Publications.

Ranis, G. and F. Stewart (2010) Success and Failure in Human Development, 1970-2007. Human Development Research Paper 2010/10, New York: UNDP-HDRO.

Ravallion, M. (2011) On Multidimensional Indices of Poverty. Journal of Economic Inequality, 9(2): 235248.

Ravallion, M. and M. Huppi (1991) Measuring Changes in Poverty: A Methodological Case Study of Indonesia During an Adjustment Period. World Bank Economic Review, 5(1): 57-82.

Robeyns, I. (2003) Sen's Capability Approach and Gender Inequality: Selecting Relevant Capabilities. Feminist Economics, 9(2/3): 61-92. 
Roche, J. M. (2008) Monitoring Inequality among Social Groups: A Methodology Combining Fuzzy Set Theory and Principal Component Analysis. Journal of Human Development, 9(3): 427-452.

Roche, J. M. (2012) Shapley Decomposition of Change over Time for the Alkire \& Foster Adjusted Fgt Class of Multidimensional Poverty Measures (M $\mathrm{M})$. Oxford Poverty and Human Development Initiative Work in Progress, Oxford: University of Oxford.

Roelen, K. and L. Camfield (2012) A Mixed-Method Taxonomy of Child Poverty - the Case of Ethiopia. Applied Research in Quality of Life, October: 1-19.

Roelen, K., F. Gassmann and C. de Neubourg (2010) Child Poverty in Vietnam: Providing Insights Using a Country-Specific and Multidimensional Model. Social Indicators Research, 98(1): 129-145.

Sen, A. K. (1976) Poverty: An Ordinal Approach to Measurement. Econometrica, 44: 219-231.

Sen, A. K. (1980) Equality of What? (1979 Tanner Lecure at Stanford). In McMurrin, S. (Ed.) The Tanner Lectures on Human Values. Salt Lake City: University of Utah Press.

Sen, A. K. (1992) Inequality Reexamined. Oxford: Clarendon Press.

Sen, A. K. (2004) Dialogue Capabilities, List, and Public Reason: Continuing the Conversation, and Interview with Amartya Sen, Conducted by Bina Agarwal, Jane Humphries and Ingrid Robeyns. Feminist Economics, 10(3): 77-80.

Shorrocks, A. (1999) Decomposition Procedures for Distributional Analysis: A Unified Framework Based on the Shapley Value. Journal of Economic Inequality: 1-28.

Tsui, K. (2002) Multidimensional Poverty Indices. Social Choice and Welfare, 19(1): 69-93.

UNDP (2010a) Beyond the Midpoint: Achieving the Millennium Development Goals. New York: Palgrave Macmillan.

UNDP (2010b) Human Development Report 2010. 20th Anniversary Edition, the Real Wealth of Nations: Pathways to Human Development. New York: Palgrave Macmillan.

UNICEF (2004) The State of the World's Children 2005: Childhood under Threat. New York: UNICEF.

UNICEF (2007) Global Study on Child Poverty and Disparity 2007-2008. New York: Global Policy Section, Division of Policy and Planning, UNICEF.

UNICEF (2010) Narrowing the Gaps to Meet the Goals. New York.

United Nations (1995) The Copenhagen Declaration and Programme of Action: World Summit for Social Development 6-12 March 1995. New York: United Nations Department of Publications.

WHO (2006) Who Child Growth Standards : Length/Height-for-Age, Weight-for-Age, Weight-for-Length, Weight-for-Height and Body Mass Index-for-Age:Methods and Development. Geneva: World Health Organization, Department of Nutrition for Health and Development.

WHO/UNICEF (2006) Core Questions on Drinking-Water and Sanitation for Household Surveys. Geneva: World Health Organization.

World Bank (2008) Poverty Assessment for Bangladesh: Creating Opportunities and Bridging the East-West Divide. Bangladesh Development Series Paper No. 26.

World Bank (2012) World Development Indicators 2012. Washington, DC. Data retrieved December 18, 2012. 


\section{Appendix 1 \\ Technical note on the Alkire and Foster Method}

This note presents the Alkire and Foster (2007, 2011a) methodology with special attention to the adjusted headcount ratio. First the notation is defined before moving on to the methodology. The notation has been adapted to the case of children.

Notation: Let $y=\left[y_{i j}\right]$ denote the $n \times d$ matrix of achievements, where $n$ represents the number of children, $d$ is the number of dimensions, and $y_{i j} \geq 0$ is the achievement of child $i=(1,2, \ldots n)$ in dimension $j=(1,2, \ldots d)$. Each row vector $y_{i \bullet}=\left(y_{i 1}, y_{i 2}, \ldots, y_{i d}\right)$ lists a child's achievements, while each column vector $y_{\bullet j}=\left(y_{1 j}, y_{2 j}, \ldots, y_{n d}\right)$ gives the distribution of dimension $j$ achievements across the set of children. Let $z_{j}>0$ denotes the deprivation cutoff below which a child is considered to be deprived in dimension $j$, and let $z$ be the row vector of dimension specific cutoff. Let $w_{j}$ denote the weight of dimension $j$ where $\sum_{j=1}^{d} w_{j}=1$. The expression $|v|$ denotes the sum of all the elements of any vector or matrix $v$, and $\mu(v)$ represents the mean of $|v|$, or $|v|$ divided by the total number of elements in $v$.

Deprivation matrix: For a given matrix of achievements $y$, it is possible to define a matrix of deprivation $g^{0}=\left[g_{i j}^{0}\right]$ whose typical element $g_{i j}^{0}$ is defined by $g_{i j}^{0}=w_{j}$ when $y_{i j}<z_{j}$, while $g_{i j}^{0}=0$ otherwise. Hence, $g^{0}$ is a $n \times d$ matrix whose $i j^{\text {th }}$ entry is the weight for dimension $j$ when child $i$ is deprived in that dimension, and 0 otherwise according to each deprivation cutoff $z_{j}$. From this matrix, we can construct a column vector $c$ of deprivation counts, whose $i^{\text {th }}$ entry $c_{i}=\left|g_{i}^{0}\right|$ represents the number of weighted deprivations suffered by child $i$. Notice that the matrix $g^{0}$ and vector $c$ can be defined for any ordinal and cardinal variable from the matrix of achievements $y$.

Identification: The vector $c$ of deprivation counts is compared against a poverty cutoff $k$ to identify the multidimensionally poor, where $0<k<1$. Hence, the identification method $\rho_{k}$ is defined as $\rho_{k}\left(y_{i} ; z\right)=1$ whenever $c_{i} \geq k$, and $\rho_{k}\left(y_{i} ; z\right)=0$ whenever $c_{i}<k$. Finally, the set of children who are multidimensionally poor is defined as $Z_{k}=\left\{i: \rho_{k}\left(y_{i} ; z\right)\right\}$. In other words, the method identifies as poor any child who is deprived in more than $k$ number of weighted dimensions. This is a dual cutoff method because it first applies the deprivation cutoff $z_{j}$ to determine who is deprived in each dimension, and then the poverty cutoff $k$ to determine the minimum number of weighted deprivations for a child to be considered multidimensionally poor. 
The headcount ratio: The headcount ratio $H=H(y ; z)$, or the percentage of children who are poor, is defined by:

$$
H=q / n
$$

where $q=q(y ; z)$ is the number of children in the set $Z_{k}$, as identified using the $\rho_{k}$ dual cutoff method.

Censored deprivation matrix: Given the deprivation matrix $g^{0}$ and poverty cutoff $k$, a censored deprivation matrix $g^{0}(k)=\left[g_{i j}^{0}(k)\right]$ is defined whose typical element $g_{i j}^{0}(k)=w_{j}$ if $c_{i} \geq k$ and $g_{i j}^{0}(k)=0$ otherwise. A censored vector of deprivation counts $c_{i}(k)$ is defined so that if $c_{i} \geq k$, then $c_{i}(k)=c_{i}$; and if $c_{i}<k$, then $c_{i}(k)=0$. This is to say that in $c_{i}(k)$ the count of deprivations is always zero for those children who are not poor according to the $\rho_{k}$ dual cutoff method, while children who were identified as poor keep the original vector of deprivation counts $c_{i}$. Then, $c_{i}(k)$ represents the share of weighted deprivations experienced by a poor child $i$.

Intensity of poverty: The intensity of poverty is defined as the average deprivations share across the poor and is given by:

(2) $\quad A=|c(k)| /(q)$

Adjusted headcount ratio: The adjusted headcount ratio $M_{0}(y ; z)$ is the average of the censored deprivation matrix, so it is given by:

(3) $\quad M_{0}=\mu\left(g_{i j}^{0}(k)\right)$

The adjusted headcount ratio can also be expressed as the product of the headcount ratio $H$ and the average deprivation share across the poor $A$ :

$$
M_{0}=H A
$$

Raw headcount: The raw headcount of dimension $j$ represents the proportion of deprived people in dimension $j$, given by:

(5) $\operatorname{Raw}_{j}=\left|g_{j}^{0}\right| / n$

Censored headcount: The censored headcount represents the proportion deprived and poor people in dimension $j$. It is computed from the censored deprivation matrix by:

(6) $C h_{j}=\left|g_{j}^{0}(k)\right| / n$ 
Subgroup decomposability: An attractive property of $M_{0}$ is that it can be decomposed by population subgroups. The decomposition is obtained by:

$$
\text { (7) } \quad M_{0}=\sum_{\ell=1}^{m} v_{\ell} M_{0 \ell}
$$

where $M_{0_{\ell}}$ denotes the adjusted headcount and $v_{\ell}$ the population share of subgroup $\ell$ from a total of $m$ subgroups $(\ell=1, \ldots, m)$, such as $v_{\ell}=n_{\ell} / n$. In other words, overall poverty is the weighted average of subgroup poverty levels, where weights are subgroup population shares. Therefore, the contribution of group $g$ to $M_{0}$ is given by:

$$
\operatorname{Contr}_{\ell}=v_{\ell} M_{0 \ell} / M_{0}
$$

Dimensional decomposability: Given that $M_{0}=\mu\left(g_{i j}^{0}(k)\right)$, it is also possible to break down the adjusted headcount by dimensions after the identification step. The (post-identification) contribution of each dimension $j$ to $M_{0}$ is given by:

(9) $\quad$ Contr $_{j}=\left|g_{j}^{0}(k)\right| / M_{0}$ 


\section{Appendix 2}

\section{Measures of Depth and Severity of Child Poverty}

This note outlines the measures proposed by Delamonica and Minujin (2007) with similar notations as in Appendix 1.

Depth of child poverty: This is the average number of deprivations suffered by children in a given population and is given by

$$
\text { Depth }=\sum_{=1}^{n} c_{i} /(n)
$$

where $c_{i}$ represents the number of weighted deprivations suffered by child $i$ divided by the total number of children. In the original proposal Delamonica and Minujin (2007) assume equal weight across dimensions but this can be modified depending on the purpose of the measure.

Severity (Weighted-Depth) of child poverty: This is equivalent to the depth of child poverty but it adds weight (i.e. importance) to the children who suffer more deprivation and so is given by

$$
\text { Severity_WD }=\sum_{=1}^{n}\left(c_{i}\right)^{2} /(n)
$$

Severity (standard deviation of Depth) of child poverty: This is based on the standard deviation given by:

$$
\text { Severity_SdD }=\sqrt{\sum_{i=1}^{n}\left(c_{i}-\left|c_{i}\right|\right)^{2} /(n)}
$$

Depth of child poverty as percentage of indicator: Note that Roelen et al. (2010) normalize the depth by the total number of indicators, so it is expressed as percentage of indicator. Following this, equation (10) would be given by:

$$
\text { Depth_\% }=\sum_{i=1}^{n}\left(c_{i} * 100\right) /(d * n)
$$

where $d$ represents the total number of dimensions. A variant in Roelen et al. (2010) is that the number of indicators varies depending on the age group of the child which is adjusted in the 'normalized' depth. Also, dimensions are measured with more than one indicator following a union approach, so a child is deprived in dimension $d$ if the child is deprived in any of the indicators within the dimension. 


\section{Appendix 3 \\ Technical note on Shapley decomposition of change in the Adjusted Headcount $\left(M_{0}\right)^{5}$}

Shapley decomposition of change in poverty by subgroup: Following a similar decomposition of change in FGT income poverty measures (Ravallion and Huppi 1991) and a Shapley value decomposition approach (Shorrocks 1999), the variation in poverty level can be broken down into: 1) changes due to intra-sectoral or within-group poverty effect and 2) changes due to demographic or intersectoral effect by:

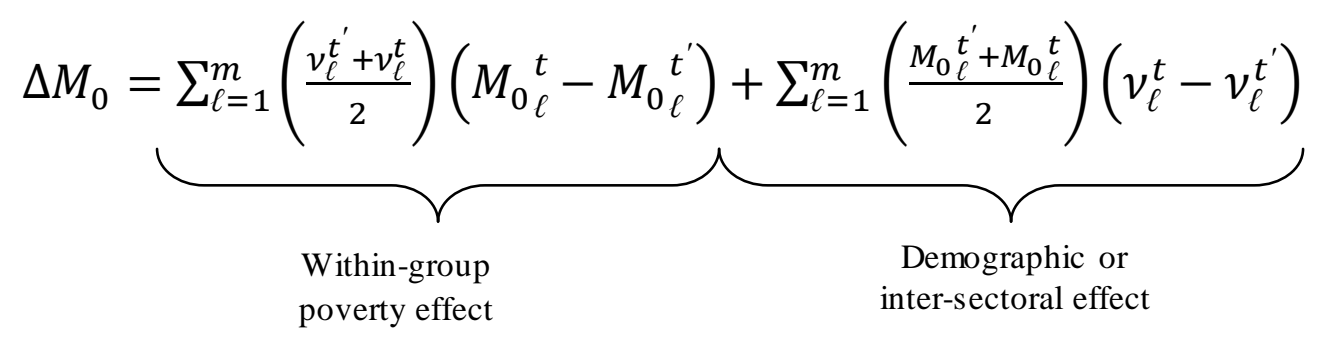

where $\Delta M_{0}=\left(M_{0}^{t}-M_{0}^{t^{\prime}}\right)$ denotes the total variation of the adjusted headcount ratio between time period $t$ and time period $t^{\prime}, M_{0 \ell}^{t}$ denotes the adjusted headcount ratio and $v_{\ell}^{t}$ the population share of subgroup $\ell$ from a total of $m$ subgroups $(\ell=1, \ldots, m)$ in two time periods respectively $\left(t, t^{\prime}\right)$. Note that the Shapley decomposition allows obtaining the marginal contribution of the within-group effect and of the demographic effect (see applications in monetary measures with FGT in: Duclos and Araar 2006).

\section{Shapley decomposition of change in poverty by incidence and intensity:}

The adjusted headcount ratio can be expressed as the product of the multidimensional incidence and intensity of poverty among the poor, $M_{0}=H * A$. Hence, the Shapley decomposition technique (Shorrocks 1999) can be applied to decompose absolute variation in the adjusted headcount ratio into an incidence effect and an intensity effect as follows: 6

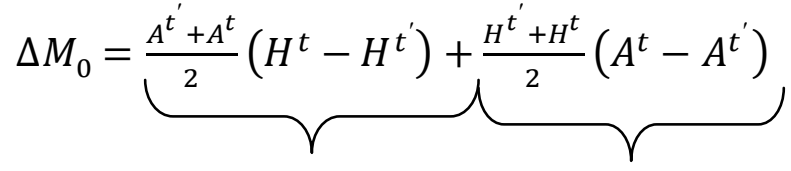

$$
\begin{aligned}
& \text { Incidence of } \\
& \text { Intensity of } \\
& \text { poverty effect } \\
& \text { poverty effect }
\end{aligned}
$$

where $H^{t}$ and $A^{t}$ respectively denote the headcount ratio and the intensity of poverty at time $t$.

\footnotetext{
5 This is an extract from a forthcoming paper from Roche (2012) which is currently in a work in progress status. For further details please contact the author.

6 The result is similar to decompositions by Apablaza and Yalonetzky (2011) but based on absolute variation. Both approaches have their merits, but absolute variations of poverty level are easier to interpret, which is an advantage for policy. Note that decomposition of FGT income poverty measures is frequently undertaken based on absolute variation (Dudos and Araar 2006; Ravallion and Huppi 1991; Shorrocks 1999).
} 
Decomposition of the variation in intensity of poverty by dimension: The AF intensity of poverty $A$, is the average deprivation share across the poor, $A=|C(k)| / q$. Thus, one might want to decompose changes in intensity of poverty by changes in the deprivations experienced by the poor in each particular dimension. Following Apablaza and Yalonetzky (2011), we know that $A^{t}=\sum_{j=1}^{d} w_{j} A_{j}^{t}$ where $w_{j}$ denotes the dimensional weight, with $\sum_{j=1}^{d} w_{j}=1$, and $A_{j}^{t}$ is the share of the poor who are deprived in dimension $j$ at time $t$.

When dimensional weight is constant across the period, the absolute change in intensity can be decomposed as follows:

$$
\Delta A=\sum_{j=1}^{d} w_{j}\left(A_{j}^{2}-A_{j}^{1}\right)
$$

Note that $A_{j}^{t}$ can also be expressed as $A_{j}^{t}=C H_{j}^{t} / H^{t}$; where $C H_{j}^{t}$ is the censored headcount ratio of dimension $j$ in time $t$ as defined in Appendix 1, and $H^{t}$ represents the proportion of poor people $n / q$. Hence equation (16) can conveniently be expressed as a function of the censored headcount ratio in each dimension as:

$$
\Delta A=\sum_{j=1}^{d} w_{d}\left(C H_{j}^{2} / H_{H^{2}}-C H_{j}^{1} / H^{1}\right)
$$

Integrated decompositions: It might be convenient to undertake an integrated analysis such as combining the decomposition of changes in poverty by subgroup (equation 14), with the decomposition by its components (equation 15), and decomposition by dimensions (equation 17) as follows:

$$
\begin{aligned}
\Delta M_{0}=\sum_{\ell=1}^{m} & \left(\frac{M_{0 \ell}^{t^{\prime}}+M_{0_{\ell}}^{t}}{2}\right)\left(v_{\ell}^{t}-v_{\ell}^{t^{\prime}}\right)+\sum_{\ell=1}^{m}\left(\frac{v_{\ell}^{t^{\prime}}+v_{\ell}^{t}}{2}\right)\left(\frac{A_{\ell}^{t^{\prime}}+A_{\ell}^{t}}{2}\right)\left(H_{\ell}^{t}-H_{\ell}^{t^{\prime}}\right) \\
& +\sum_{\ell=1}^{m}\left(\frac{v_{\ell}^{t^{\prime}}+v_{\ell}^{t}}{2}\right)\left(\frac{H_{\ell}^{t^{\prime}}+H_{\ell}^{t}}{2}\right) \sum_{j=1}^{d} w_{d}\left(\frac{C H_{j}^{2}}{H^{2}}-\frac{C H_{j}^{1}}{H^{1}}\right)
\end{aligned}
$$


Table A1: Comparison among different measures of intensity of child poverty

by region in Bangladesh, 1997, 2000, 2004 and 2007

\begin{tabular}{|c|c|c|c|c|c|c|c|c|c|c|c|c|c|c|c|c|}
\hline \multirow{3}{*}{ Bangladesh } & \multirow[b]{2}{*}{1997} & \multirow[b]{2}{*}{2000} & \multirow[b]{2}{*}{2004} & \multirow[b]{2}{*}{2007} & \multicolumn{6}{|c|}{ Absolute Variation } & \multicolumn{6}{|c|}{ Relative Variation } \\
\hline & & & & & \multicolumn{2}{|c|}{$1997-2000$} & \multicolumn{2}{|c|}{$2000-2004$} & \multicolumn{2}{|c|}{$2004-2007$} & \multicolumn{2}{|c|}{$1997-2000$} & \multicolumn{2}{|c|}{$2000-2004$} & \multicolumn{2}{|c|}{ 2004-2007 } \\
\hline & & & & & & & & & & & & & & & & \\
\hline Intensity for $\mathrm{k}=1(\mathrm{AF})$ & $61.0 \%$ & $56.9 \%$ & $55.9 \%$ & $50.4 \%$ & $-4.2 \%$ & $* * *$ & $-0.9 \%$ & & $-5.5 \%$ & $* * *$ & $-6.9 \%$ & $* * *$ & $-1.6 \%$ & & $-9.8 \%$ & $* * *$ \\
\hline Intensity for $\mathrm{k}=2(\mathrm{AF})$ & $62.9 \%$ & $60.1 \%$ & $58.5 \%$ & $54.4 \%$ & $-2.7 \%$ & $* * *$ & $-1.6 \%$ & * & $-4.2 \%$ & $* * *$ & $-4.3 \%$ & $* * *$ & $-2.7 \%$ & * & $-7.1 \%$ & $* * *$ \\
\hline Intensity for $\mathrm{k}=3(\mathrm{AF})$ & $66.9 \%$ & $65.3 \%$ & $63.6 \%$ & $61.1 \%$ & $-1.6 \%$ & $* * *$ & $-1.7 \%$ & $* * *$ & $-2.5 \%$ & $* * *$ & $-2.4 \%$ & $* * *$ & $-2.6 \%$ & $* * *$ & $-3.9 \%$ & $* * *$ \\
\hline Depth as $\%$ indicators (RGN) & $59.9 \%$ & $55.6 \%$ & $54.6 \%$ & $48.6 \%$ & $-4.3 \%$ & $* * *$ & $-1.0 \%$ & & $-5.9 \%$ & $* * *$ & $-7.2 \%$ & $* * *$ & $-1.8 \%$ & & $-10.8 \%$ & $* * *$ \\
\hline Depth (DM) & 3.6 & 3.3 & 3.3 & 2.9 & -0.3 & $* * *$ & -0.1 & & -0.4 & $* * *$ & $-7.2 \%$ & $* * *$ & $-1.8 \%$ & & $-10.8 \%$ & $* * *$ \\
\hline Weighted Depth (DM) & 14.4 & 12.7 & 12.2 & 10.1 & -1.6 & $* * *$ & -0.6 & & -2.1 & $* * *$ & $-11.3 \%$ & $* * *$ & $-4.4 \%$ & & $-17.4 \%$ & $* * *$ \\
\hline Severity (DM) & 5.0 & 5.0 & 4.7 & 4.5 & -0.1 & $* * *$ & -0.2 & & -0.3 & $* * *$ & $-1.6 \%$ & $* * *$ & $-4.6 \%$ & & $-5.9 \%$ & $* * *$ \\
\hline \multicolumn{17}{|l|}{ Barisal } \\
\hline Intensity for $\mathrm{k}=1(\mathrm{AF})$ & $59.2 \%$ & $55.8 \%$ & $57.6 \%$ & $54.0 \%$ & $-3.4 \%$ & & $1.8 \%$ & & $-3.6 \%$ & * & $-5.8 \%$ & & $3.3 \%$ & & $-6.3 \%$ & * \\
\hline Intensity for $\mathrm{k}=2(\mathrm{AF})$ & $61.4 \%$ & $58.8 \%$ & $59.8 \%$ & $56.3 \%$ & $-2.5 \%$ & & $1.0 \%$ & & $-3.5 \%$ & ** & $-4.1 \%$ & & $1.6 \%$ & & $-5.8 \%$ & $* *$ \\
\hline Intensity for $\mathrm{k}=3(\mathrm{AF})$ & $66.9 \%$ & $63.6 \%$ & $63.9 \%$ & $61.5 \%$ & $-3.3 \%$ & $*$ & $0.3 \%$ & & $-2.4 \%$ & $*$ & $-4.9 \%$ & $*$ & $0.5 \%$ & & $-3.8 \%$ & $*$ \\
\hline Depth as $\%$ indicators (RGN) & $59.0 \%$ & $55.2 \%$ & $57.2 \%$ & $53.3 \%$ & $-3.9 \%$ & & $2.1 \%$ & & $-3.9 \%$ & * & $-6.6 \%$ & & $3.7 \%$ & & $-6.8 \%$ & * \\
\hline Depth (DM) & 3.5 & 3.3 & 3.4 & 3.2 & -0.2 & & 0.1 & & -0.2 & * & $-6.6 \%$ & & $3.7 \%$ & & $-6.8 \%$ & * \\
\hline Weighted Depth (DM) & 14.0 & 12.3 & 13.0 & 11.4 & -1.6 & & 0.7 & & -1.6 & * & $-11.7 \%$ & & $5.6 \%$ & & $-12.3 \%$ & * \\
\hline Severity (DM) & 4.9 & 4.7 & 4.7 & 4.4 & -0.3 & & 0.0 & & -0.3 & $*$ & $-5.3 \%$ & & $-0.3 \%$ & & $-6.0 \%$ & $*$ \\
\hline \multicolumn{17}{|l|}{ Chittagong } \\
\hline Intensity for $\mathrm{k}=1(\mathrm{AF})$ & $60.1 \%$ & $54.2 \%$ & $56.3 \%$ & $49.9 \%$ & $-5.9 \%$ & $* * *$ & $2.1 \%$ & & $-6.4 \%$ & $* * *$ & $-9.8 \%$ & $* * *$ & $3.9 \%$ & & $-11.4 \%$ & *** \\
\hline Intensity for $\mathrm{k}=2(\mathrm{AF})$ & $62.2 \%$ & $58.3 \%$ & $58.9 \%$ & $54.9 \%$ & $-3.9 \%$ & $* * *$ & $0.6 \%$ & & $-4.0 \%$ & $* *$ & $-6.2 \%$ & $* * *$ & $1.1 \%$ & & $-6.8 \%$ & $* *$ \\
\hline Intensity for $\mathrm{k}=3(\mathrm{AF})$ & $66.3 \%$ & $64.7 \%$ & $64.3 \%$ & $62.4 \%$ & $-1.6 \%$ & & $-0.5 \%$ & & $-1.8 \%$ & $*$ & $-2.4 \%$ & & $-0.7 \%$ & & $-2.9 \%$ & $*$ \\
\hline Depth as $\%$ indicators (RGN) & $58.9 \%$ & $53.1 \%$ & $54.9 \%$ & $47.6 \%$ & $-5.8 \%$ & $* * *$ & $1.8 \%$ & & $-7.3 \%$ & $* * *$ & $-9.9 \%$ & $* * *$ & $3.4 \%$ & & $-13.2 \%$ & $* * *$ \\
\hline Depth (DM) & 3.5 & 3.2 & 3.3 & 2.9 & -0.4 & $* * *$ & 0.1 & & -0.4 & $* * *$ & $-9.9 \%$ & $* * *$ & $3.4 \%$ & & $-13.2 \%$ & $* * *$ \\
\hline Weighted Depth (DM) & 14.0 & 11.8 & 12.3 & 10.0 & -2.1 & $* * *$ & 0.5 & & -2.4 & $* * *$ & $-15.3 \%$ & $* * *$ & $4.5 \%$ & & $-19.2 \%$ & $* * *$ \\
\hline Severity (DM) & 5.0 & 4.9 & 4.8 & 4.7 & -0.1 & $* * *$ & -0.1 & & -0.1 & $* * *$ & $-2.7 \%$ & $* * *$ & $-1.3 \%$ & & $-2.5 \%$ & $* * *$ \\
\hline \multicolumn{17}{|l|}{ Dhaka } \\
\hline Intensity for $\mathrm{k}=1(\mathrm{AF})$ & $62.6 \%$ & $57.1 \%$ & $55.8 \%$ & $50.1 \%$ & $-5.5 \%$ & $* * *$ & $-1.2 \%$ & & $-5.7 \%$ & $* * *$ & $-8.8 \%$ & *** & $-2.2 \%$ & & $-10.2 \%$ & $* * *$ \\
\hline Intensity for $\mathrm{k}=2(\mathrm{AF})$ & $64.6 \%$ & $60.7 \%$ & $58.4 \%$ & $54.4 \%$ & $-3.8 \%$ & $* *$ & $-2.3 \%$ & $*$ & $-4.0 \%$ & $* * *$ & $-5.9 \%$ & $* *$ & $-3.8 \%$ & * & $-6.8 \%$ & $* * *$ \\
\hline Intensity for $\mathrm{k}=3(\mathrm{AF})$ & $68.2 \%$ & $65.5 \%$ & $63.4 \%$ & $60.6 \%$ & $-2.7 \%$ & ** & $-2.1 \%$ & $*$ & $-2.8 \%$ & $* *$ & $-4.0 \%$ & $* *$ & $-3.2 \%$ & * & $-4.4 \%$ & $* *$ \\
\hline Depth as \% indicators (RGN) & $60.4 \%$ & $55.6 \%$ & $54.0 \%$ & $47.8 \%$ & $-4.8 \%$ & ** & $-1.6 \%$ & & $-6.2 \%$ & $* * *$ & $-7.9 \%$ & $* *$ & $-2.9 \%$ & & $-11.5 \%$ & $* * *$ \\
\hline Depth (DM) & 3.6 & 3.3 & 3.2 & 2.9 & -0.3 & ** & -0.1 & & -0.4 & $* * *$ & -0.1 & $* *$ & 0.0 & & $-11.5 \%$ & $* * *$ \\
\hline Weighted Depth (DM) & 14.8 & 12.8 & 12.0 & 9.8 & -2.0 & ** & -0.8 & & -2.2 & $* * *$ & -0.1 & $* *$ & -0.1 & & $-18.2 \%$ & $* * *$ \\
\hline Severity (DM) & 5.3 & 5.0 & 4.7 & 4.5 & -0.2 & ** & -0.3 & & -0.3 & $* * *$ & 0.0 & $* *$ & -0.1 & & $-5.9 \%$ & $* * *$ \\
\hline
\end{tabular}

Source: Own calculations based on Demographic Health Surveys. Note: *** statistically significant at $\alpha=0.01, * *$ statistically significant at $\alpha=0.05, *$ statistically significant at $\alpha=0.10$, It corresponds to a t-test hypothesis test for the difference betw een both years, taking into account the complex sample design of the surveys. AF $=$ Alkire and Foster (2011); DM =

Delamonica and Minujin (2007), RGN = Roelen, Gassmann \& de Neubourg (2010) 
Continuation table A1: Comparison among different measures of intensity of child poverty by region in Bangladesh, 1997, 2000, 2004 and 2007

\begin{tabular}{|c|c|c|c|c|c|c|c|c|c|c|c|c|c|c|c|c|}
\hline \multirow{3}{*}{ Khulna } & \multirow[b]{2}{*}{1997} & \multirow[b]{2}{*}{2000} & \multirow[b]{2}{*}{2004} & \multirow[b]{2}{*}{2007} & \multicolumn{6}{|c|}{ Absolute Variation } & \multicolumn{6}{|c|}{ Relative Variation } \\
\hline & & & & & \multicolumn{2}{|c|}{$1997-2000$} & \multicolumn{2}{|c|}{ 2000-2004 } & \multicolumn{2}{|c|}{ 2004-2007 } & \multicolumn{2}{|c|}{$1997-2000$} & \multicolumn{2}{|c|}{$2000-2004$} & \multicolumn{2}{|c|}{ 2004-2007 } \\
\hline & & & & & & & & & & & & & & & & \\
\hline Intensity for $\mathrm{k}=1(\mathrm{AF})$ & $55.3 \%$ & $52.7 \%$ & $51.9 \%$ & $46.9 \%$ & $-2.6 \%$ & & $-0.8 \%$ & & $-4.9 \%$ & ** & $-4.7 \%$ & & $-1.6 \%$ & & $-9.5 \%$ & ** \\
\hline Intensity for $\mathrm{k}=2(\mathrm{AF})$ & $57.6 \%$ & $56.8 \%$ & $56.2 \%$ & $51.4 \%$ & $-0.8 \%$ & & $-0.6 \%$ & & $-4.8 \%$ & $* * *$ & $-1.4 \%$ & & $-1.1 \%$ & & $-8.5 \%$ & *** \\
\hline Intensity for $\mathrm{k}=3(\mathrm{AF})$ & $62.8 \%$ & $63.3 \%$ & $62.6 \%$ & $59.5 \%$ & $0.5 \%$ & & $-0.7 \%$ & & $-3.2 \%$ & ** & $0.8 \%$ & & $-1.0 \%$ & & $-5.1 \%$ & ** \\
\hline Depth as $\%$ indicators (RGN) & $54.5 \%$ & $49.7 \%$ & $50.1 \%$ & $45.1 \%$ & $-4.8 \%$ & $* *$ & $0.4 \%$ & & $-5.0 \%$ & ** & $-8.8 \%$ & ** & $0.8 \%$ & & $-10.1 \%$ & $* *$ \\
\hline Depth (DM) & 3.3 & 3.0 & 3.0 & 2.7 & -0.3 & ** & 0.0 & & -0.3 & ** & -0.1 & ** & 0.0 & & $-10.1 \%$ & $* *$ \\
\hline Weighted Depth (DM) & 12.0 & 10.8 & 10.7 & 8.7 & -1.2 & & -0.1 & & -2.0 & $* * *$ & -0.1 & & 0.0 & & $-18.5 \%$ & $* * *$ \\
\hline Severity (DM) & 4.6 & 4.9 & 4.7 & 4.1 & 0.3 & & -0.2 & & -0.6 & $* * *$ & 0.1 & & 0.0 & & $-12.0 \%$ & *** \\
\hline \multicolumn{17}{|l|}{ Rajshahi } \\
\hline Intensity for $\mathrm{k}=1(\mathrm{AF})$ & $61.4 \%$ & $58.9 \%$ & $56.3 \%$ & $50.1 \%$ & $-2.5 \%$ & $*$ & $-2.6 \%$ & $*$ & $-6.1 \%$ & *** & $-4.1 \%$ & $*$ & $-4.4 \%$ & $*$ & $-10.9 \%$ & *** \\
\hline Intensity for $\mathrm{k}=2(\mathrm{AF})$ & $62.5 \%$ & $61.0 \%$ & $57.9 \%$ & $52.7 \%$ & $-1.5 \%$ & & $-3.1 \%$ & $* * *$ & $-5.2 \%$ & $* * *$ & $-2.5 \%$ & & $-5.1 \%$ & $* * *$ & $-9.0 \%$ & *** \\
\hline Intensity for $\mathrm{k}=3(\mathrm{AF})$ & $66.1 \%$ & $65.2 \%$ & $62.1 \%$ & $59.3 \%$ & $-0.8 \%$ & & $-3.2 \%$ & $* * *$ & $-2.8 \%$ & $* * *$ & $-1.2 \%$ & & $-4.9 \%$ & $* * *$ & $-4.5 \%$ & $* * *$ \\
\hline Depth as \% indicators (RGN) & $60.9 \%$ & $58.2 \%$ & $55.7 \%$ & $48.9 \%$ & $-2.8 \%$ & * & $-2.5 \%$ & * & $-6.8 \%$ & $* * *$ & $-4.6 \%$ & * & $-4.3 \%$ & $*$ & $-12.2 \%$ & *** \\
\hline Depth (DM) & 3.7 & 3.5 & 3.3 & 2.9 & -0.2 & * & -0.1 & $*$ & -0.4 & $* * *$ & 0.0 & $*$ & 0.0 & $*$ & $-12.2 \%$ & *** \\
\hline Weighted Depth (DM) & 14.5 & 13.5 & 12.2 & 9.8 & -1.0 & $*$ & -1.2 & $* *$ & -2.4 & $* * *$ & -0.1 & $*$ & -0.1 & $* *$ & $-19.8 \%$ & $* * *$ \\
\hline Severity (DM) & 4.8 & 4.8 & 4.4 & 4.2 & 0.0 & $*$ & -0.4 & & -0.3 & **** & 0.0 & $*$ & -0.1 & & $-6.1 \%$ & $* * *$ \\
\hline \multicolumn{17}{|l|}{ Sylhet } \\
\hline Intensity for $\mathrm{k}=1(\mathrm{AF})$ & $67.1 \%$ & $64.0 \%$ & $58.7 \%$ & $54.8 \%$ & $-3.1 \%$ & & $-5.2 \%$ & $*$ & $-4.0 \%$ & & $-4.6 \%$ & & $-8.2 \%$ & $*$ & $-6.8 \%$ & \\
\hline Intensity for $\mathrm{k}=2(\mathrm{AF})$ & $67.9 \%$ & $65.6 \%$ & $61.8 \%$ & $58.5 \%$ & $-2.2 \%$ & & $-3.9 \%$ & & $-3.2 \%$ & & $-3.3 \%$ & & $-5.9 \%$ & & $-5.3 \%$ & \\
\hline Intensity for $\mathrm{k}=3(\mathrm{AF})$ & $71.3 \%$ & $69.4 \%$ & $67.6 \%$ & $65.5 \%$ & $-1.9 \%$ & & $-1.8 \%$ & & $-2.2 \%$ & & $-2.7 \%$ & & $-2.6 \%$ & & $-3.2 \%$ & \\
\hline Depth as \% indicators (RGN) & $66.5 \%$ & $62.9 \%$ & $56.8 \%$ & $54.1 \%$ & $-3.6 \%$ & & $-6.0 \%$ & * & $-2.7 \%$ & & $-5.5 \%$ & & $-9.6 \%$ & * & $-4.7 \%$ & \\
\hline Depth (DM) & 4.0 & 3.8 & 3.4 & 3.2 & -0.2 & & -0.4 & $*$ & -0.2 & & -0.1 & & -0.1 & $*$ & $-4.7 \%$ & \\
\hline Weighted Depth (DM) & 17.3 & 15.8 & 13.5 & 12.2 & -1.5 & & -2.2 & & -1.4 & & -0.1 & & -0.1 & & $-10.3 \%$ & \\
\hline Severity (DM) & 5.3 & 5.3 & 5.3 & 4.9 & 0.0 & & 0.0 & & -0.5 & & 0.0 & & 0.0 & & $-9.1 \%$ & \\
\hline
\end{tabular}

Source: Own calculations based on Demographic Health Surveys. Note: *** statistically significant at $\alpha=0.01, * *$ statistically significant at $\alpha=0.05, *$ statistically significant at $\alpha=0.10$, It corresponds to a t-test hypothesis test for the difference betw een both years, taking into account the complex sample design of the surveys. AF = Alkire and Foster (2011); DM = Delamonica and Minujin (2007), RGN = Roelen, Gassmann \& de Neubourg (2010) 
Table A2: Level and variation in the censored headcount ratio for each indicator by region in Bangladesh, 1997, 2000, 2004 and 2007

\begin{tabular}{|c|c|c|c|c|c|c|c|c|c|c|c|c|c|c|c|c|}
\hline \multirow[b]{3}{*}{ Bangladesh } & \multirow[b]{2}{*}{1997} & \multirow[b]{2}{*}{2000} & \multirow[b]{2}{*}{2004} & \multirow[b]{2}{*}{2007} & \multicolumn{6}{|c|}{ Absolute Variation } & \multicolumn{6}{|c|}{ Relative Variation } \\
\hline & & & & & \multicolumn{2}{|c|}{$1997-2000$} & \multicolumn{2}{|c|}{$2000-2004$} & \multicolumn{2}{|c|}{$2004-2007$} & \multicolumn{2}{|c|}{$1997-2000$} & \multicolumn{2}{|c|}{$2000-2004$} & \multicolumn{2}{|c|}{ 2004-2007 } \\
\hline & & & & & & & & & & & & & & & & \\
\hline Health & $41.3 \%$ & $37.1 \%$ & $25.5 \%$ & $18.3 \%$ & $-4.1 \%$ & $* *$ & $-11.7 \%$ & $* * *$ & $-7.2 \%$ & $* * *$ & $-10.0 \%$ & $* *$ & $-31.4 \%$ & $* * *$ & $-28.2 \%$ & $* * *$ \\
\hline Water & $4.6 \%$ & $3.4 \%$ & $3.3 \%$ & $2.9 \%$ & $-1.2 \%$ & & $-0.1 \%$ & & $-0.3 \%$ & & $-27.1 \%$ & & $-3.2 \%$ & & $-10.6 \%$ & \\
\hline Sanitation & $69.8 \%$ & $63.8 \%$ & $70.8 \%$ & $52.0 \%$ & $-6.0 \%$ & $* * *$ & $7.0 \%$ & $* * *$ & $-18.8 \%$ & $* * *$ & $-8.7 \%$ & $* * *$ & $11.0 \%$ & $* * *$ & $-26.5 \%$ & $* * *$ \\
\hline Shelter & $82.6 \%$ & $75.4 \%$ & $76.1 \%$ & $65.3 \%$ & $-7.3 \%$ & $* * *$ & $0.7 \%$ & & $-10.8 \%$ & $* * *$ & $-8.8 \%$ & $* * *$ & $1.0 \%$ & & $-14.2 \%$ & $* * *$ \\
\hline Information & $66.0 \%$ & $61.3 \%$ & $59.5 \%$ & $52.9 \%$ & $-4.7 \%$ & $* * *$ & $-1.8 \%$ & & $-6.6 \%$ & $* * *$ & $-7.1 \%$ & $* * *$ & $-2.9 \%$ & & $-11.2 \%$ & $* * *$ \\
\hline \multicolumn{17}{|l|}{ Barisal } \\
\hline Health & $31.7 \%$ & $31.5 \%$ & $27.3 \%$ & $18.7 \%$ & $-0.2 \%$ & & $-4.2 \%$ & & $-8.5 \%$ & ** & $-0.6 \%$ & & $-13.4 \%$ & & $-31.3 \%$ & $* *$ \\
\hline Nutrition & $68.5 \%$ & $58.1 \%$ & $59.4 \%$ & $56.2 \%$ & $-10.4 \%$ & ** & $1.3 \%$ & & $-3.3 \%$ & & $-15.2 \%$ & $* *$ & $2.3 \%$ & & $-5.5 \%$ & \\
\hline Water & $9.9 \%$ & $3.3 \%$ & $4.3 \%$ & $2.1 \%$ & $-6.6 \%$ & & $1.1 \%$ & & $-2.2 \%$ & & $-66.9 \%$ & & $32.7 \%$ & & $-51.0 \%$ & \\
\hline Sanitation & $64.8 \%$ & $57.1 \%$ & $76.4 \%$ & $61.0 \%$ & $-7.7 \%$ & & $19.3 \%$ & $* * *$ & $-15.4 \%$ & $* * *$ & $-11.9 \%$ & & $33.8 \%$ & $* * *$ & $-20.2 \%$ & $* * *$ \\
\hline Shelter & $78.7 \%$ & $77.0 \%$ & $81.6 \%$ & $75.9 \%$ & $-1.7 \%$ & & $4.6 \%$ & & $-5.7 \%$ & & $-2.2 \%$ & & $6.0 \%$ & & $-7.0 \%$ & \\
\hline Information & $64.5 \%$ & $67.8 \%$ & $63.8 \%$ & $66.0 \%$ & $3.3 \%$ & & $-4.0 \%$ & & $2.2 \%$ & & $5.1 \%$ & & $-5.9 \%$ & & $3.4 \%$ & \\
\hline \multicolumn{17}{|l|}{ Chittagong } \\
\hline Health & $46.6 \%$ & $31.8 \%$ & $27.9 \%$ & $22.4 \%$ & $-14.8 \%$ & $* * *$ & $-4.0 \%$ & & $-5.5 \%$ & & $-31.7 \%$ & $* * *$ & $-12.4 \%$ & & $-19.6 \%$ & \\
\hline Water & $1.8 \%$ & $3.3 \%$ & $4.1 \%$ & $3.9 \%$ & $1.5 \%$ & & $0.8 \%$ & & $-0.2 \%$ & & $84.9 \%$ & & $23.8 \%$ & & $-4.1 \%$ & \\
\hline Sanitation & $64.0 \%$ & $56.5 \%$ & $70.2 \%$ & $47.3 \%$ & $-7.6 \%$ & & $13.8 \%$ & $* * *$ & $-22.9 \%$ & $* * *$ & $-11.8 \%$ & & $24.4 \%$ & $* * *$ & $-32.6 \%$ & $* * *$ \\
\hline Shelter & $81.9 \%$ & $69.6 \%$ & $75.4 \%$ & $61.2 \%$ & $-12.3 \%$ & $* * *$ & $5.8 \%$ & & $-14.2 \%$ & $* * *$ & $-15.1 \%$ & $* * *$ & $8.4 \%$ & & $-18.9 \%$ & $* * *$ \\
\hline Information & $61.0 \%$ & $57.9 \%$ & $57.1 \%$ & $47.0 \%$ & $-3.1 \%$ & & $-0.8 \%$ & & $-10.0 \%$ & $* *$ & $-5.1 \%$ & & $-1.4 \%$ & & $-17.6 \%$ & $* *$ \\
\hline \multicolumn{17}{|l|}{ Dhaka } \\
\hline Health & $44.4 \%$ & $41.2 \%$ & $25.7 \%$ & $19.2 \%$ & $-3.2 \%$ & & $-15.5 \%$ & $* * *$ & $-6.5 \%$ & ** & $-7.1 \%$ & & $-37.7 \%$ & $* * *$ & $-25.3 \%$ & $* *$ \\
\hline Nutrition & $67.6 \%$ & $56.4 \%$ & $56.5 \%$ & $48.4 \%$ & $-11.2 \%$ & $* * *$ & $0.1 \%$ & & $-8.0 \%$ & $* *$ & $-16.6 \%$ & $* * *$ & $0.2 \%$ & & $-14.2 \%$ & $* *$ \\
\hline Water & $3.2 \%$ & $1.3 \%$ & $0.3 \%$ & $0.9 \%$ & $-1.9 \%$ & & $-1.0 \%$ & * & $0.6 \%$ & & $-59.2 \%$ & & $-75.8 \%$ & $*$ & $201.2 \%$ & \\
\hline Sanitation & $72.4 \%$ & $66.1 \%$ & $70.2 \%$ & $51.6 \%$ & $-6.3 \%$ & & $4.1 \%$ & & $-18.6 \%$ & $* * *$ & $-8.6 \%$ & & $6.2 \%$ & & $-26.5 \%$ & $* * *$ \\
\hline Shelter & $82.7 \%$ & $75.2 \%$ & $75.6 \%$ & $65.2 \%$ & $-7.4 \%$ & $* *$ & $0.3 \%$ & & $-10.3 \%$ & $* *$ & $-9.0 \%$ & $* *$ & $0.4 \%$ & & $-13.7 \%$ & $* *$ \\
\hline Information & $68.9 \%$ & $58.8 \%$ & $59.6 \%$ & $52.2 \%$ & $-10.1 \%$ & $* * *$ & $0.8 \%$ & & $-7.5 \%$ & $*$ & $-14.6 \%$ & $* * *$ & $1.4 \%$ & & $-12.5 \%$ & $*$ \\
\hline
\end{tabular}

Source: Own calculations based on Demographic Health Surveys.

Note: *** statistically significant at $\alpha=0.01, * *$ statistically significant at $\alpha=0.05, *$ statistically significant at $\alpha=0.10$. It corresponds to a $\mathrm{t}$-test hypothesis test for the difference betw een

both years, taking into account the complex sample design of the survevs. 
Continuation Table A2: Level and variation in the censored headcount ratio for each indicator by region in Bangladesh, 1997, 2000, 2004 and 2007

\begin{tabular}{|c|c|c|c|c|c|c|c|c|c|c|c|c|c|c|c|c|}
\hline \multirow{2}{*}{ Khulna } & \multirow[b]{2}{*}{1997} & \multirow[b]{2}{*}{2000} & \multirow[b]{2}{*}{2004} & \multirow[b]{2}{*}{2007} & \multicolumn{6}{|c|}{ Absolute Variation } & \multicolumn{6}{|c|}{ Relative Variation } \\
\hline & & & & & \multicolumn{2}{|c|}{$1997-2000$} & \multicolumn{2}{|c|}{$2000-2004$} & \multicolumn{2}{|c|}{$2004-2007$} & \multicolumn{2}{|c|}{$1997-2000$} & \multicolumn{2}{|c|}{$2000-2004$} & \multicolumn{2}{|c|}{$2004-2007$} \\
\hline Health & $28.7 \%$ & $25.9 \%$ & $18.1 \%$ & $10.0 \%$ & $-2.8 \%$ & & $-7.8 \%$ & $* *$ & $-8.1 \%$ & $* * *$ & $-9.8 \%$ & & $-30.2 \%$ & $* *$ & $-44.9 \%$ & $* * *$ \\
\hline Nutrition & $62.6 \%$ & $47.9 \%$ & $48.5 \%$ & $40.5 \%$ & $-14.7 \%$ & $* * *$ & $0.6 \%$ & & $-8.0 \%$ & $*$ & $-23.4 \%$ & $* * *$ & $1.2 \%$ & & $-16.5 \%$ & $*$ \\
\hline Water & $3.2 \%$ & $5.4 \%$ & $6.6 \%$ & $6.4 \%$ & $2.2 \%$ & & $1.3 \%$ & & $-0.3 \%$ & & $69.4 \%$ & & $23.8 \%$ & & $-3.9 \%$ & \\
\hline Sanitation & $59.0 \%$ & $52.8 \%$ & $61.1 \%$ & $47.5 \%$ & $-6.2 \%$ & & $8.3 \%$ & $*$ & $-13.6 \%$ & $* * *$ & $-10.5 \%$ & & $15.6 \%$ & $*$ & $-22.3 \%$ & $* * *$ \\
\hline Shelter & $76.4 \%$ & $66.3 \%$ & $66.7 \%$ & $57.9 \%$ & $-10.1 \%$ & $* *$ & $0.4 \%$ & & $-8.8 \%$ & $*$ & $-13.2 \%$ & $* *$ & $0.6 \%$ & & $-13.2 \%$ & $*$ \\
\hline Information & $59.0 \%$ & $53.8 \%$ & $51.4 \%$ & $44.4 \%$ & $-5.2 \%$ & & $-2.4 \%$ & & $-7.0 \%$ & $*$ & $-8.7 \%$ & & $-4.5 \%$ & & $-13.5 \%$ & $*$ \\
\hline \multicolumn{17}{|l|}{ Rajshahi } \\
\hline Health & $37.0 \%$ & $39.4 \%$ & $22.9 \%$ & $12.9 \%$ & $2.4 \%$ & & $-16.6 \%$ & $* * *$ & $-10.0 \%$ & *** & $6.6 \%$ & & $-42.0 \%$ & $* * *$ & $-43.7 \%$ & *** \\
\hline Nutrition & $68.1 \%$ & $57.9 \%$ & $55.1 \%$ & $48.8 \%$ & $-10.3 \%$ & $* * *$ & $-2.8 \%$ & & $-6.3 \%$ & $*$ & $-15.1 \%$ & $* * *$ & $-4.8 \%$ & & $-11.4 \%$ & $*$ \\
\hline Water & $5.2 \%$ & $2.4 \%$ & $1.0 \%$ & $1.1 \%$ & $-2.9 \%$ & & $-1.4 \%$ & & $0.1 \%$ & & $-54.8 \%$ & & $-58.7 \%$ & & $14.6 \%$ & \\
\hline Sanitation & $76.8 \%$ & $71.1 \%$ & $77.0 \%$ & $54.1 \%$ & $-5.7 \%$ & & $5.9 \%$ & & $-22.9 \%$ & $* * *$ & $-7.4 \%$ & & $8.4 \%$ & & $-29.7 \%$ & $* * *$ \\
\hline Shelter & $85.9 \%$ & $81.5 \%$ & $81.3 \%$ & $67.6 \%$ & $-4.4 \%$ & $*$ & $-0.3 \%$ & & $-13.7 \%$ & $* * *$ & $-5.1 \%$ & $*$ & $-0.3 \%$ & & $-16.8 \%$ & $* * *$ \\
\hline Information & $69.2 \%$ & $66.8 \%$ & $65.3 \%$ & $55.8 \%$ & $-2.4 \%$ & & $-1.5 \%$ & & $-9.5 \%$ & $* *$ & $-3.5 \%$ & & $-2.2 \%$ & & $-14.6 \%$ & $* *$ \\
\hline \multicolumn{17}{|l|}{ Sylhet } \\
\hline Health & $49.7 \%$ & $49.1 \%$ & $34.0 \%$ & $27.8 \%$ & $-0.7 \%$ & & $-15.1 \%$ & $* * *$ & $-6.2 \%$ & & $-1.3 \%$ & & $-30.8 \%$ & $* * *$ & $-18.1 \%$ & \\
\hline Nutrition & $75.2 \%$ & $64.6 \%$ & $57.9 \%$ & $51.0 \%$ & $-10.6 \%$ & $* * *$ & $-6.7 \%$ & & $-6.8 \%$ & & $-14.1 \%$ & $* * *$ & $-10.4 \%$ & & $-11.8 \%$ & \\
\hline Water & $16.5 \%$ & $12.6 \%$ & $12.9 \%$ & $8.5 \%$ & $-3.9 \%$ & & $0.4 \%$ & & $-4.4 \%$ & & $-23.7 \%$ & & $2.9 \%$ & & $-34.0 \%$ & \\
\hline Sanitation & $78.1 \%$ & $73.5 \%$ & $66.4 \%$ & $57.5 \%$ & $-4.6 \%$ & & $-7.1 \%$ & & $-8.9 \%$ & & $-5.8 \%$ & & $-9.7 \%$ & & $-13.4 \%$ & \\
\hline Shelter & $88.1 \%$ & $84.8 \%$ & $74.7 \%$ & $70.2 \%$ & $-3.4 \%$ & & $-10.1 \%$ & $* *$ & $-4.4 \%$ & & $-3.8 \%$ & & $-11.9 \%$ & $* *$ & $-5.9 \%$ & \\
\hline Information & $72.0 \%$ & $69.3 \%$ & $57.6 \%$ & $61.9 \%$ & $-2.7 \%$ & & $-11.7 \%$ & $* *$ & $4.3 \%$ & & $-3.8 \%$ & & $-16.9 \%$ & $* *$ & $7.4 \%$ & \\
\hline
\end{tabular}

Source: Own calculations based on Demographic Health Surveys.

Note: ${ }^{* * *}$ statistically significant at $\alpha=0.01,{ }^{* *}$ statistically significant at $\alpha=0.05, *$ statistically significant at $\alpha=0.10$. It corresponds to a t-test hypothesis test for the difference between both years, taking into account the complex sample design of the surveys. 
Table A3: Level and variation in the raw headcount ratio for each indicator by region in Bangladesh, 1997, 2000, 2004 and 2007

\begin{tabular}{|c|c|c|c|c|c|c|c|c|c|c|c|c|c|c|c|c|}
\hline \multirow{3}{*}{ Bangladesh } & \multirow[b]{2}{*}{1997} & \multirow[b]{2}{*}{2000} & \multirow[b]{2}{*}{2004} & \multirow[b]{2}{*}{2007} & \multicolumn{6}{|c|}{ Absolute Variation } & \multicolumn{6}{|c|}{ Relative Variation } \\
\hline & & & & & \multicolumn{2}{|c|}{$1997-2000$} & \multicolumn{2}{|c|}{$2000-2004$} & \multicolumn{2}{|c|}{$2004-2007$} & \multicolumn{2}{|c|}{$1997-2000$} & \multicolumn{2}{|c|}{$2000-2004$} & \multicolumn{2}{|c|}{$2004-2007$} \\
\hline & & & & & & & & & & & & & & & & \\
\hline Health & $43.5 \%$ & $39.8 \%$ & $26.7 \%$ & $19.9 \%$ & $-3.7 \%$ & $* *$ & $-13.2 \%$ & $* * *$ & $-6.7 \%$ & $* * *$ & $-8.4 \%$ & ** & $-33.1 \%$ & **** & $-25.3 \%$ & *** \\
\hline Water & $4.7 \%$ & $3.6 \%$ & $3.4 \%$ & $3.1 \%$ & $-1.1 \%$ & & $-0.2 \%$ & & $-0.3 \%$ & & $-23.0 \%$ & & $-5.8 \%$ & & $-8.1 \%$ & \\
\hline Sanitation & $72.5 \%$ & $68.4 \%$ & $79.1 \%$ & $58.3 \%$ & $-4.1 \%$ & $* *$ & $10.7 \%$ & $* * *$ & $-20.7 \%$ & $* * *$ & $-5.7 \%$ & $* *$ & $15.7 \%$ & $* * *$ & $-26.2 \%$ & $* * *$ \\
\hline Shelter & $95.9 \%$ & $94.1 \%$ & $94.6 \%$ & $93.5 \%$ & $-1.8 \%$ & $* *$ & $0.6 \%$ & & $-1.1 \%$ & & $-1.9 \%$ & $* *$ & $0.6 \%$ & & $-1.2 \%$ & \\
\hline Information & $68.5 \%$ & $65.3 \%$ & $62.2 \%$ & $58.7 \%$ & $-3.2 \%$ & $*$ & $-3.1 \%$ & $*$ & $-3.5 \%$ & $*$ & $-4.7 \%$ & $*$ & $-4.7 \%$ & $*$ & $-5.6 \%$ & $*$ \\
\hline \multicolumn{17}{|l|}{ Barisal } \\
\hline Health & $35.4 \%$ & $35.0 \%$ & $28.1 \%$ & $19.7 \%$ & $-0.4 \%$ & & $-6.9 \%$ & & $-8.5 \%$ & ** & $-1.2 \%$ & & $-19.6 \%$ & & $-30.1 \%$ & ** \\
\hline Nutrition & $77.5 \%$ & $62.5 \%$ & $62.4 \%$ & $63.4 \%$ & $-15.0 \%$ & $* * *$ & $-0.1 \%$ & & $1.0 \%$ & & $-19.3 \%$ & $* * *$ & $-0.2 \%$ & & $1.6 \%$ & \\
\hline Water & $9.9 \%$ & $3.3 \%$ & $4.4 \%$ & $2.5 \%$ & $-6.6 \%$ & & $1.1 \%$ & & $-1.9 \%$ & & $-66.9 \%$ & & $34.9 \%$ & & $-42.6 \%$ & \\
\hline Sanitation & $67.3 \%$ & $59.9 \%$ & $83.4 \%$ & $64.5 \%$ & $-7.4 \%$ & & $23.5 \%$ & $* * *$ & $-18.9 \%$ & $* * *$ & $-11.0 \%$ & & $39.2 \%$ & $* * *$ & $-22.7 \%$ & $* * *$ \\
\hline Shelter & $96.8 \%$ & $97.4 \%$ & $98.8 \%$ & $98.1 \%$ & $0.6 \%$ & & $1.4 \%$ & & $-0.7 \%$ & & $0.7 \%$ & & $1.5 \%$ & & $-0.7 \%$ & \\
\hline Information & $67.4 \%$ & $72.9 \%$ & $66.2 \%$ & $71.7 \%$ & $5.5 \%$ & & $-6.7 \%$ & & $5.5 \%$ & & $8.1 \%$ & & $-9.2 \%$ & & $8.3 \%$ & \\
\hline \multicolumn{17}{|l|}{ Chittagong } \\
\hline Health & $48.7 \%$ & $35.1 \%$ & $29.0 \%$ & $24.5 \%$ & $-13.5 \%$ & $* * *$ & $-6.2 \%$ & * & $-4.5 \%$ & & $-27.8 \%$ & $* * *$ & $-17.6 \%$ & $*$ & $-15.5 \%$ & \\
\hline Water & $1.8 \%$ & $3.5 \%$ & $4.1 \%$ & $4.2 \%$ & $1.7 \%$ & & $0.6 \%$ & & $0.1 \%$ & & $96.7 \%$ & & $16.4 \%$ & & $2.4 \%$ & \\
\hline Sanitation & $66.8 \%$ & $61.1 \%$ & $79.2 \%$ & $52.8 \%$ & $-5.7 \%$ & & $18.1 \%$ & $* * *$ & $-26.4 \%$ & $* * *$ & $-8.5 \%$ & & $29.6 \%$ & $* * *$ & $-33.4 \%$ & $* * *$ \\
\hline Shelter & $96.7 \%$ & $94.7 \%$ & $94.6 \%$ & $92.3 \%$ & $-2.0 \%$ & & $-0.1 \%$ & & $-2.3 \%$ & & $-2.0 \%$ & & $-0.1 \%$ & & $-2.4 \%$ & \\
\hline Information & $63.7 \%$ & $61.5 \%$ & $58.9 \%$ & $53.3 \%$ & $-2.2 \%$ & & $-2.6 \%$ & & $-5.6 \%$ & & $-3.5 \%$ & & $-4.2 \%$ & & $-9.5 \%$ & \\
\hline \multicolumn{17}{|l|}{ Dhaka } \\
\hline Health & $46.8 \%$ & $43.5 \%$ & $27.2 \%$ & $21.3 \%$ & $-3.3 \%$ & & $-16.3 \%$ & $* * *$ & $-6.0 \%$ & $* *$ & $-7.0 \%$ & & $-37.4 \%$ & $* * *$ & $-21.9 \%$ & $* *$ \\
\hline Nutrition & $72.7 \%$ & $62.4 \%$ & $62.5 \%$ & $57.5 \%$ & $-10.3 \%$ & $* * *$ & $0.0 \%$ & & $-4.9 \%$ & & $-14.2 \%$ & $* * *$ & $0.1 \%$ & & $-7.9 \%$ & \\
\hline Water & $3.3 \%$ & $1.4 \%$ & $0.4 \%$ & $1.0 \%$ & $-1.9 \%$ & & $-1.0 \%$ & * & $0.6 \%$ & & $-57.3 \%$ & & $-69.6 \%$ & $*$ & $147.3 \%$ & \\
\hline Sanitation & $75.1 \%$ & $73.1 \%$ & $78.9 \%$ & $57.1 \%$ & $-2.1 \%$ & & $5.8 \%$ & & $-21.8 \%$ & $* * *$ & $-2.7 \%$ & & $8.0 \%$ & & $-27.6 \%$ & $* * *$ \\
\hline Shelter & $93.9 \%$ & $91.6 \%$ & $92.6 \%$ & $91.8 \%$ & $-2.2 \%$ & & $1.0 \%$ & & $-0.8 \%$ & & $-2.4 \%$ & & $1.0 \%$ & & $-0.8 \%$ & \\
\hline Information & $70.6 \%$ & $61.7 \%$ & $62.3 \%$ & $57.9 \%$ & $-8.9 \%$ & $* * *$ & $0.6 \%$ & & $-4.4 \%$ & & $-12.6 \%$ & $* * *$ & $1.0 \%$ & & $-7.1 \%$ & \\
\hline
\end{tabular}

Source: Own calculations based on Demographic Health Surveys.

Note: *** statistically significant at $\alpha=0.01,{ }^{* *}$ statistically significant at $\alpha=0.05, *$ statistically significant at $\alpha=0.10$. It corresponds to a t-test hypothesis test for the difference between both years, taking into account the complex sample design of the surveys. 
Continuation table A3: Level and variation in the raw headcount ratio for each indicator by region in Bangladesh, 1997, 2000, 2004 and 2007

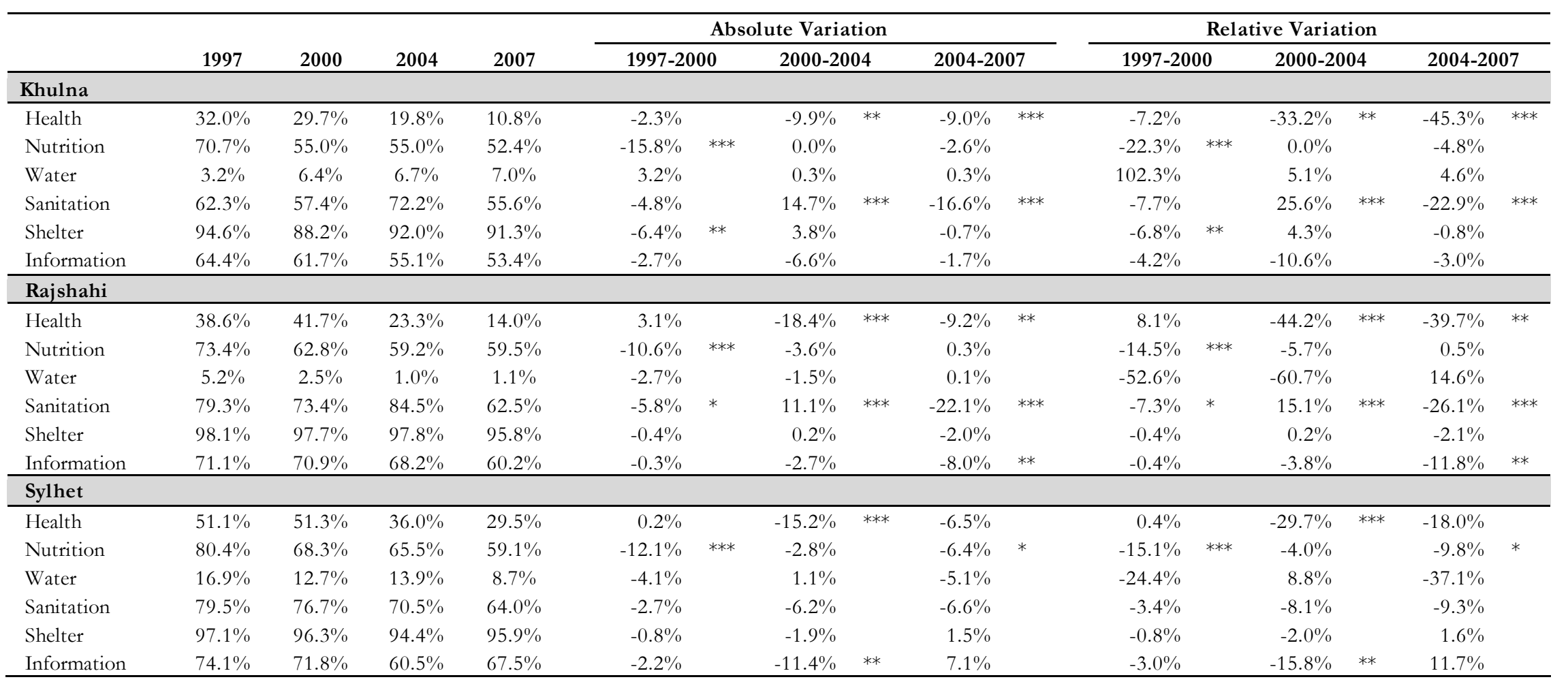

Source: $\quad$ Own calculations based on Demographic Health Surveys.

Note: $\quad * * *$ statistically significant at $\alpha=0.01,{ }^{* *}$ statistically significant at $\alpha=0.05,{ }^{*}$ statistically significant at $\alpha=0.10$. It corresponds to a $\mathrm{t}$-test hypothesis test for the difference between both years, taking into account the complex sample design of the surveys. 


\section{Appendix A1}

Figure A1: Robustness checks of poverty cutoffs (k) in changes in multidimensional poverty over time for divisions in Bangladesh 1997-2004
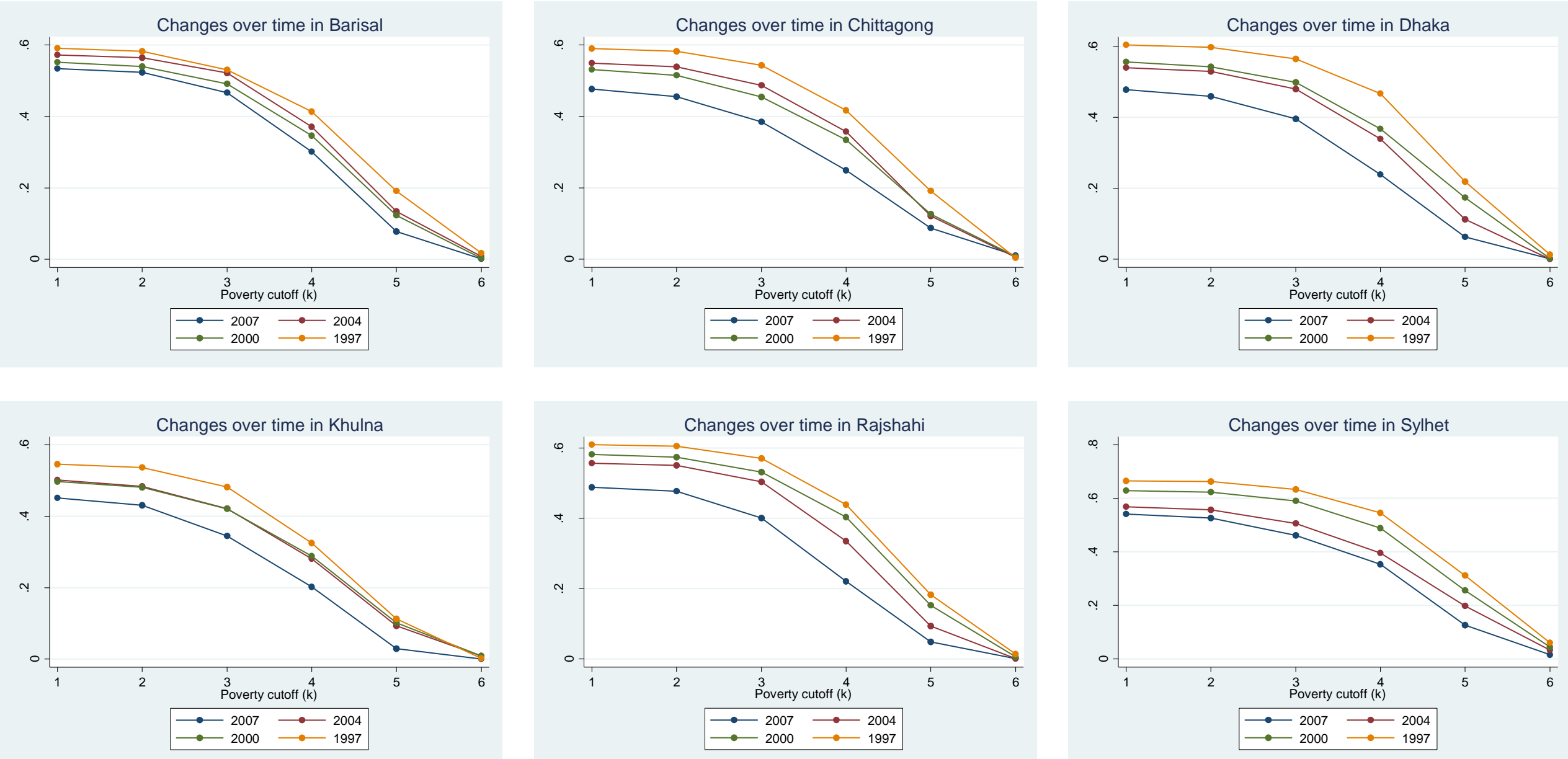


\section{Appendix A2}

Figure A2: Robustness checks of different poverty cutoffs $(k)$ in ranking among provinces across time
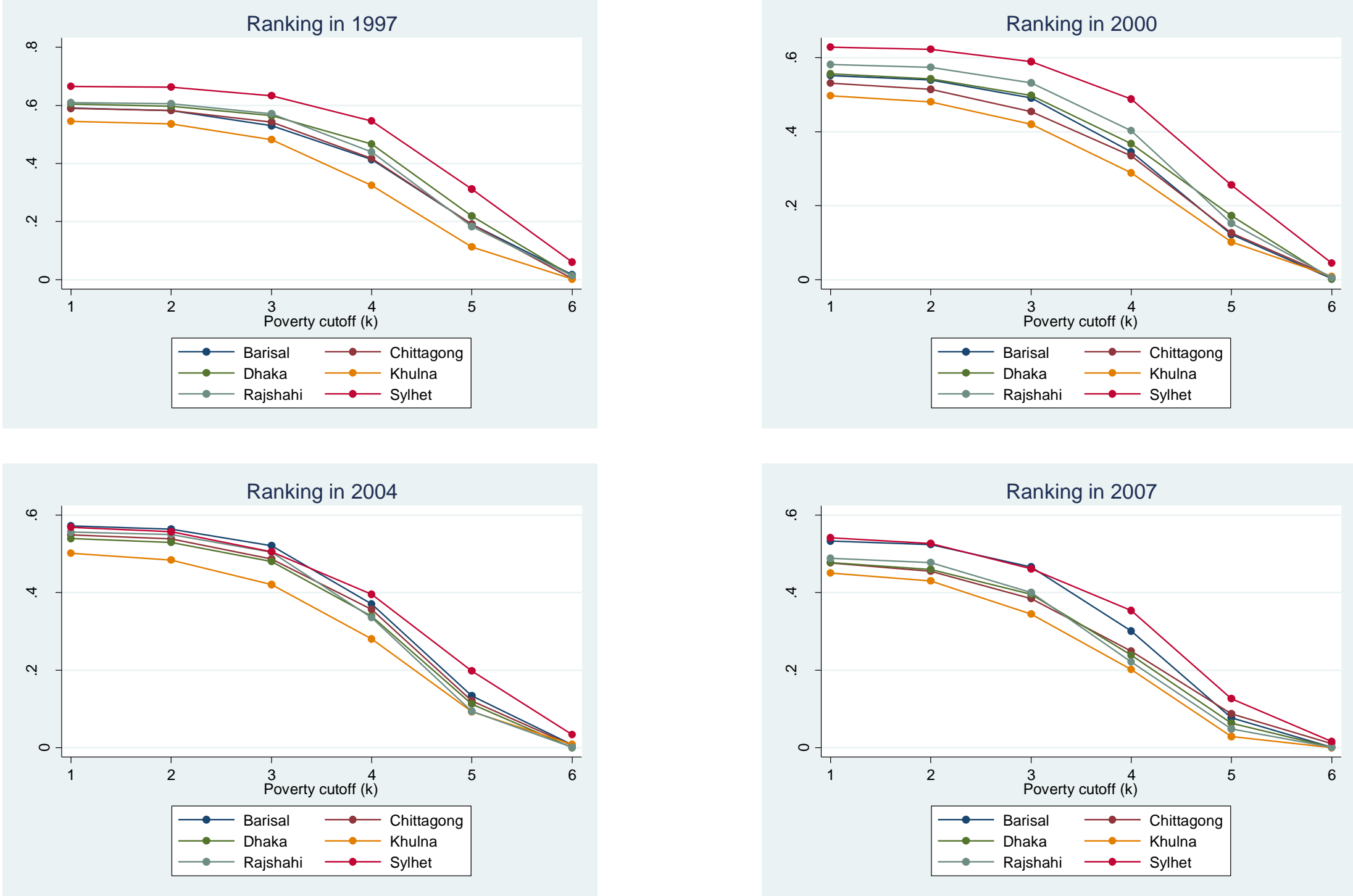